\title{
Market Power and Cost Efficiencies in Banking ${ }^{1}$
}

\author{
Pradeep Kumar ${ }^{2}$ \\ University of Exeter Business School, Department of Economics, Exeter, U.K.
}

February 7, 2018

\begin{abstract}
Existing studies that quantify cost efficiencies in the banking industry do not account for local market power. If market power is ignored and increases with size, it gets counted as additional cost efficiencies which leads to an over-prediction. I address this limitation by developing a model of the demand for consumer deposits at the geographic market level and cost efficiencies at the firm level. Incorporating the network structure of banks in the analysis increases dimensionality of the bank's choice set and also the possibility of multiple equilibria. To address these issues, I use moment inequality methods to estimate the cost parameters. Using a panel data from the U.S. banking industry, I find that the evidence of cost efficiencies is weak, at best, for all the banks. Using the estimated parameters, I simulate six mergers between banks of different sizes. In the short run, all the simulated mergers show dis-economies of scale on average. However, most of them show an increase in consumer welfare as the market power (or oligopoly) effect is dominated by an increase in the local branch density.
\end{abstract}

JEL Classification: L1, L2, D2, G21

Keywords: Banking Industry, Cost Efficiency, Market Power, Moment Inequality

\footnotetext{
${ }^{1}$ I gratefully acknowledge the help and support of my dissertation committee: Keith Crocker, Paul Grieco, Mark Roberts and Jim Tybout. I am also thankful for very insightful discussions with Gaurab Aryal, Jonathon Eaton, Kala Krishna, Vikram Kumar, Yao Luo, Robert Marshall, Peter Newberry, Felix Tintelnot, Van Anh Vuong, Neil Wallace, Steve Yeaple, Hongsong Zhang and participants of the Empirical IO workshop at the Penn State University. All remaining errors are my own. I am also thankful to the Human Capital Foundation for their generous financial support.

${ }^{2}$ Email: p.kumar@exeter.ac.uk
} 


\section{Introduction}

A common assumption in estimating efficiencies using a cost function approach is that firms are price takers. Although modeling assumptions are best considered by developing an understanding of the industry being studied, the assumption of price taking behavior can be difficult to motivate in certain industries. Firms with high market power can get more favorable prices and if the variation in market power with firms' size is systematic, the estimation of cost efficiencies can be biased. Also, a modeling challenge occurs if multimarket and single-market firms compete locally in a market, as a firm-level model to estimate a cost function needs to combined with a market-level demand side accounting for the market power. In this paper, I explore this idea using data from the U.S. banking industry.

The removal of legal restrictions on intrastate and interstate banking in the U.S. was a gradual process that culminated with passage of the Riegle-Neal Act in 1994. Since then, the banking industry has undergone substantial restructuring. This gradual deregulation has led to a consolidation of banks over the last 30 years and that is still ongoing. In 1990, there were 12,343 commercial banks and 2,815 savings banks insured by the FDIC in the United States. In 2012, these numbers had fallen to 6,222 commercial banks and 1,024 savings banks. ${ }^{3}$ This consolidation has been driven primarily by mergers. As the number of banks has declined, the average size of banks, measured by deposits, has risen from 184 million dollars in 1990 to 557 million dollars (normalized to 1990 dollars) in 2012.

This change in market structure caused by mergers can have many implications for consumers, banks and regulators. Anti-trust regulators evaluate such scenarios by comparing gains generated by cost efficiencies to the market power losses for an economy. From an industrial organization viewpoint, consumer utility, market power and cost efficiencies are the three important elements at the center stage of this industry consolidation. Quantifying geographically local forces such as market power and consumer utility along side firm-level cost efficiencies in the same model causes curse-of-dimensionality and multiple Nash equilibriums to arise due to the implicit network structure. I use moment inequality methods with a demand model for differentiated products to disentangle and separately identify cost efficiencies from market power. The results imply little efficiency gains for banks as they grow in size. I also find that consumers derive a higher utility from larger banks and an increased number of local branches. Although the cost efficiencies are absent, merger simulations show an overall increase in consumer welfare in most cases because consumers' utility from a larger bank size and increased number of local bank branches dominates the oligopoly price effects.

The presence of market power in the banking industry is well documented by Prager

\footnotetext{
${ }^{3}$ Almost $98 \%$ of the banks in the U.S. were FDIC insured in 2012.
} 
and Hannan (1998), Berger, Demsetz, and Strahan (1999) and Simons and Stavins (1998). Recently, there has been an increase in empirical studies of competition and market structure in the US banking industry using structural models. Ishii (2008) studies effects of ATM surcharges on competition and welfare. Zhou (2008) looks at historical mergers to simulate prices, product quality and entry. Aguirregabiria, Clark and Wang (2016) study the effect of Riegle-Neal Act on the geographical risk diversification of banks. Corbae and D'Erasmo (2013) use a dynamic oligopoly model to study entry and exit along the business cycle in the US banking industry. Uetake and Watanabe (2012) use a matching model to endogenize the merger decision and compare entry by merger with de-novo entry. Akkus, Cookson and Hortacsu (2016) use a matching model framework to quantify merger value creation by using a revealed preference argument.

Although the findings about increase in market power with size are clear, there is a long un-resolved debate about the presence of cost efficiencies in banking. Studies by Boyd and Graham (1998), Mester (1987), Berger, Hanweck and Humphrey (1987), and Boyd and Runkle (1993) did not find economies of scale beyond very small banks. These studies used data from the 1980s and didn't incorporate risk aspects of banking into the production technology. More recently, Hughes, Mester, and Moon (2001), Hughes, Lang, Mester, and Moon (1996), Hughes and Mester (1998) found significant economies of scale in most banks when capital structure and endogenous risk taking were explicitly considered in the analyses of production.

The above studies which calculate firm-level cost efficiencies do not account for market power at the local geographic level. It is possible that the change in costs with size could be different if we control for the local market power. For example, if the larger banks have more price setting power in the deposits market they would incur lower interest expenses, a cost component in most studies, as compared to the smaller banks. This would lead to an over-prediction of cost efficiencies.

Market power leading to a mis-measurement of cost efficiencies has more general implications than the banking industry alone. For example, in the food industry it is well established that there is significant market power in the inputs market, such as for the purchase of seeds, fertilizers or live animals (Schroeter (1988), Azzam and Pagoulatos (1990), Wann and Sexton (1992), Kim et. al (2002)). If the larger firms have more monopsony/oligopsony power in the inputs market, cost efficiencies measured simply using a variation in accounting costs with size will be biased since part of the reduction in cost will be driven by a reduction in expenditure on raw materials due to an increased market power and not due to an efficient technology. A similar issue may also arise in the gasoline industry. Previous studies report a presence of market power affecting the gasoline prices in the industry (Borenstein (1991), 
Barron, Taylor, and Umbeck (2001)). One of the major suggested cause of market power is the vertical integration between retailers and upstream gasoline refiners. Hastings and Gilbert (2005) find that mergers between the gasoline refining and retailing firms in the US west coast gasoline market provided strategic advantage by increasing competitors' input costs. This change is market structure led to a relative reduction in input costs of the acquiring firm in the gasoline retailing market. If the acquiring firm is larger in size, which is usually the case in mergers, the measurement of cost efficiencies will be overestimated if market power is not accounted for.

It is important to include a market-level demand side because a bank is setting its deposit interest rate (and hence incurring the interest expenses) in response to the consumers' utility and the rival banks which are present in various imperfectly competitive markets. Otherwise identical banks may have different interest expenses due to varying degree of competition present in the markets and if we ignore the market level demand side this variation in interest expenses can lead to a bias in the cost parameters. Including market demand in a firm-level entry model gives rise to a decision by a bank on its network structure across various markets. I use moment inequalities to estimate the network choice parameters. This has three main benefits. First, it is robust to the large dimensionality of the network choice problem. Second, the estimated parameters are more reliable as we are using weaker assumptions. Moment inequalities rely only on the necessary condition of the Nash equilibrium for estimation, there is no equilibrium selection mechanism involved like most entry models. ${ }^{4}$ Third, moment inequality methods account for the possibility of multiple equilibria. Our model is partially identified and each set of estimated parameters corresponds to an equilibrium that is consistent with the data.

Another aspect that is particular to the banking industry and is relatively unexplored is the consumers' preference for a large network of branches and the capitalization level of a bank. Consumers prefer large network of branches not only due to geographical convenience, but also because larger banks are deemed safer to bankruptcy risk. Equity capital measures the safety of a bank since it is the bank's cushion against losses. The quality of a bank in the demand model is measured by number of branches, local branch density, capital-size ratio and geographic dispersion of a bank. I find that the quality-effects constitute an important driver of consumers' utility for deposit services, even more important than interest rates.

I develop a three-stage empirical model of banking that captures the long-run effects of establishing a branch network and short-run effects due to price competition and capital structure. In the first stage, all banks simultaneously choose their network of branches.

\footnotetext{
${ }^{4}$ Since the equilibrium selection rules cannot be tested in the data, findings of the models which use them are less reliable.
} 
The network decision comprises the number of branches to open and their location. In the second stage, banks choose equity capital. Equity capital is needed for three reasons: to satisfy government regulation constraints, signal safety to uninsured depositors, and as an alternative to deposits for funding loans. In the third stage, banks set deposit interest rates and compete via Bertrand competition to collect deposits in the local markets. In this stage, consumers demand deposit services and choose banks based upon their characteristics.

The empirical model is estimated in three stages. First, demand parameters are estimated using the generalized method of moments (GMM) with both supply-side and demand-side moments. Second, the cost of raising equity capital is estimated by using moments formed by the first-order condition of equity capital. Finally, the remaining cost parameters are estimated using the moment inequality method proposed in Pakes, Porter, Ho and Ishii (2015), PPHI henceforth. To form inequalities, counterfactual policies are generated using addition and subtraction of branches in different markets. For inference, I use the PPHI method as well as the generalized moment selection approach proposed by Andrews and Soares (2010).

The estimation results show that consumers prefer banks that offer high deposit rates, have more branches locally and nationwide, and are more capitalized. The cost parameters suggest a weak evidence for the presence of efficiencies. The estimated interest rate to raise equity capital for small banks (less than 300 branches) is $6.84 \%$ while for large banks (more than 300 branches) it is $5.37 \%$.

Using the estimated parameters, I simulate two mergers in each of the three categories: between two small banks, a small bank and a large bank, and between two large banks. The merger simulations analyze the effect of market power, cost efficiencies and qualityeffects on a bank's profitability by comparing the post-merger scenario to the pre-merger one. The cost efficiency in a merger is calculated by subtracting the operating cost of the two pre-merger banks from the merged bank's cost. The market power effect of a merger needs to be separated from other demand synergies (quality-effects) arising due to the consumers' preference for the size of a bank. I address this issue by subtracting the post-merger revenue of the merged bank where both market power and quality effects are present from a counterfactual post-merger scenario where only quality-effects exist.

The parameters estimated using the cost function approach correspond to a long-run equilibrium and also the cost efficiency measured is more reliable using this method since we are only imposing the necessary condition of the Nash equilibrium. But, using this approach we cannot contrast the relative importance of the market power as compared to the cost efficiencies. In this regard, the merger simulations help us to compare the magnitudes of these two effects. However, the merger analysis is valid only in the short-run as banks are 
not allowed to re-optimize their branch networks after the merger.

For all the merger simulations, there are dis-economies of scale on average. Qualityeffects always generate higher revenue for the banks as compared to the market power. This happens because the price elasticity of demand for deposits is much lower than the bank's demand elasticity for size and local branch density. Of the six mergers analyzed, five of them generate positive surplus for consumers. This welfare result is also driven by a larger demand elasticty of deposits with respect to local branch density as compared to deposit price.

The rest of the paper is organized as follows. Section 2 briefly discusses the banking industry and analyzes raw data to look for evidence of presence/absence of cost-efficiencies. Section 3 discusses the data used in the paper. Section 4 outlines the economic model. In Section 5, I discuss the estimation strategy. Section 6 contains the estimation results. Section 7 has counterfactual experiments and section 8 concludes.

\section{Industry Analysis}

The banking industry is one of the important industries in the U.S. with total assets of approximately $\$ 11.7$ trillion in 2006 . For decades, commercial banks had been geographically constrained by the McFadden Act of 1927 that prohibited them from operating across state lines. Additionally, state laws often restricted banks ability to branch across county lines and in many states prohibited branch banking entirely. The states deregulated their banking laws at different times. Some deregulated as early as 1970 whereas others were deregulated only when the Riegle-Neal Act was passed in 1994. The after effects of Riegle-Neal Act on market structure are significant. This led to a consolidation of banks over the last 30 years and is still ongoing. Since 1990, the number of banks have almost been halved to 7,402 commercial banks and 1,279 savings banks in 2006. Since the financial crisis started in 2007, the drop in the number of banks is also due to bank failures and the forced mergers of failing institutions with healthy ones, as well as regular mergers. ${ }^{5}$ In 2012, these numbers were reduced to 6,222 commercial banks and 1,024 savings banks.

All bank mergers must be approved by one of the three federal bank regulators: Office of the Comptroller of the Currency (OCC), Federal Deposit Insurance Corporation (FDIC) or Board of Governors of the Federal Reserve System (FRB). Before the onset of financial crisis in 2007, there were more than few hundred mergers per year. Table 1 shows the count of

\footnotetext{
${ }^{5} \mathrm{~A}$ regular merger is defined as a merger between two banks which are owned by separate bank holding companies and neither of the banks is a failing institution.
} 


\begin{tabular}{|c|c|c|c|}
\hline year & \# mergers (L-L) & \# mergers (S-L) & \# mergers (S-S) \\
\hline Year & L-L & S-L & S-S \\
\hline 1995 & 5 & 60 & 513 \\
\hline 1996 & 10 & 62 & 404 \\
\hline 1997 & 2 & 36 & 408 \\
\hline 1998 & 12 & 39 & 478 \\
\hline 1999 & 16 & 60 & 459 \\
\hline 2000 & 5 & 46 & 333 \\
\hline 2001 & 11 & 36 & 355 \\
\hline 2002 & 12 & 31 & 317 \\
\hline 2003 & 7 & 12 & 275 \\
\hline 2004 & 12 & 26 & 343 \\
\hline 2005 & 12 & 23 & 287 \\
\hline 2006 & 6 & 19 & 297 \\
\hline Total & 110 & 450 & 4,469 \\
\hline
\end{tabular}

Table 1: Distribution of mergers post Riegle-Neal. (L-L) corresponds to mergers between two large banks (both more than 300 branches). (S-L) corresponds to merger between a small and a large bank. (S-S) corresponds to a merger between two small banks(both smaller than 300 branches).

mergers among banks of different sizes from 1995-2006. ${ }^{6}$ The maximum number of mergers take place between two small banks (less than 300 branches) whereas the least number of mergers are between two large banks (more than 300 branches). However, the large-large mergers cause more substantial change in the market structure. Some of the mergers in the large-large category are: Citicorp and Travelers Group (1998), Wachovia and First Union Corp. (2001), Bank One Corp. and JPMorgan Chase \& Co. (2004). ${ }^{7}$

\subsection{Empirical Evidence}

Estimation results in the later part of this paper suggest that the cost efficiencies are either weak or absent in the U.S. banking industry. If this is indeed true, most mergers will lead to market power effects only. This can be tested in the data by comparing pre and post merger prices. I conduct a simple difference analysis and also estimate a difference-indifference regression model to test the hypothesis.

\footnotetext{
${ }^{6}$ Over the years OCC and FRB have published lesser details about the mergers making it difficult to distinguish between regular mergers and corporate re-organization mergers. The table is based on the numbers from FDIC data alone where a merger is inferred from the change in ownership of a bank. Hence the table includes mergers corresponding to corporate re-organizations as well.

${ }^{7}$ The trends in Table 1 are similar with size cut-offs of 50 and 500.
} 


\subsubsection{Difference Analysis}

I compare before and after merger deposit interest rates of the banks that merged between 2000-2006 using a simple difference analysis. Pre-merger observations include both acquiring bank and target bank for all years prior to the merger year. Post-merger observations include only the merged bank for all years after the merger year up to 2006. Table 2 compares the mean deposit interest rates across the two groups using a two-sample t-test with equal variances. $^{8}$ On an average, banks decrease their deposit interest rate by $0.38 \%$ after a merger. Further analysis is done for mergers between banks of various sizes. A merger between two large banks is followed by a drop in the deposit interest rates of $0.27 \%$ ( $\mathrm{t}$ stat=3.12) on an average. Mergers between a small and a large bank is followed by an average decrease in the deposit interest rates of $0.49 \%$ ( $\mathrm{t}$ stat $=6.12$ ), whereas average drop in the interest rates for a merger between two small banks is $0.39 \%$ ( $\mathrm{t}$ stat=17.68). Since most mergers lead to a decrease in the deposit interest rates, it indicates a preliminary evidence that the cost efficiencies are either weak or absent.

\begin{tabular}{c|cccccr}
\hline Group & Obs & Mean & Std. Err. & Std. Dev. & $95 \%$ Confidence Interval \\
\hline Pre-Merger & 5,091 & 0.01575 & 0.00009 & 0.0071 & {$[0.01556$} & $0.01595]$ \\
Post-Merger & 1,368 & 0.01195 & 0.00013 & 0.0048 & {$[0.01170$} & $0.01220]$ \\
\hline Difference & & 0.00380 & 0.00016 & & {$[0.00348$} & $0.00412]$ \\
\hline
\end{tabular}

Table 2: Pre and post merger comparison of deposit interest rate using two-sample t-test. A null hypothesis of equal means is rejected with p-value $<0.01$.

I conduct another analysis for all banks (merging and non-merging) and find that as banks get larger in size they set lower deposit interest rates. The correlation coefficient between the $\log$ of deposit interest rate and the log of the number of branches is -0.1827 (significant at $\alpha=0.01)$. This provides another preliminary evidence that bigger banks exercise market power. This fact is widely documented in the existing literature. Berger, Demsetz, and Strahan (1999) use data for the 1990s and find a negative relationship between local market concentration and deposit rates. Simons and Stavins (1998) find that an increase in a local concentration measure (HHI) leads to a decrease in deposit interest rates.

\footnotetext{
${ }^{8} \mathrm{~A}$ t-test with unequal variances provides a similar result.
} 


\subsubsection{Difference-in-Difference Model}

I estimate a difference-in-difference (DID) model to examine the effect of mergers on the deposit interest rates. The objective is to compare the deposit price changes of banks in markets which experienced a merger to banks in other markets (control group). There is no obvious control group as there are only 4 MSAs out of the total 345 which experienced no merger activity between 2000 and 2006. I estimate a DID model using two alternative definitions of control and treatment groups. First, markets are defined in the treatment group if the number of branches merged in any year during 2000-2005 are more than 5\% of the total branches present in that market. There are 314 such treatment markets out of the 345 total markets. This first treatment group is called the SMM (Small Merger Markets). In the second specification, treatment markets are classified as such if the number of branches merged in any year during 2000-2005 are more than $10 \%$ of the total branches in that market. There are 246 such treatment markets. This second treatment group is called the BMM (Big Merger Markets). Also, I estimate a continuous version of this DID model as a robustness check to this ad-hoc cutoff. Markets in the control group have similar characteristics to the treatment group in the before period. Refer to Appendix F for details.

Specifically, I estimate the following regression model for both definitions of the treatment groups,

$$
\begin{aligned}
P_{j m t}^{d} & =\beta_{0}+\beta_{1} \text { After }_{m t}+\beta_{2} \text { Treat }_{m}+\beta_{3} I\left(\text { After }_{m t} \times \text { Treat }_{m}\right)+\sum_{a=1}^{J} \gamma_{a} I\{a=j\} \\
& +\sum_{b=1}^{M} \nu_{b} I\{b=m\}+\beta_{4} X_{j m t}+\epsilon_{j m t}
\end{aligned}
$$

where $P_{j m t}^{d}$ is the deposit interest rate of bank $\mathrm{j}$ with presence in market $m$ in year $t$. The dummy variable, After ${ }_{m t}$, changes from 0 to 1 after the first merger occurs in a market. Since the first merger can be in a different year for each market, the before and after periods are specific to each market. This approach allows us to compare interest rates of banks in different markets which may have experienced the first merger in different years. Treat $_{m}$ is a dummy variable which is 1 for treatment markets and 0 otherwise. The $\beta_{3}$ coefficient on the interaction term $\left(\right.$ After $_{m t} \times$ Treat $\left._{m}\right)$ is our parameter of interest as it measures the effect of a merger on deposit interest rates. Firm fixed-effects and market fixed-effects are measured by parameters $\gamma_{a}$ 's and $\nu_{b}$ 's respectively and control for any level differences among banks and markets. $X_{j m t}$ is a vector of control variables to account for any change in market structure and a bank's characteristics over time. The control variables include log of a bank's size measured by the total number of branches nationwide, log of the number of branches of a 
bank $j$ in market $m$ and the number of banking firms present in the market $m .{ }^{9}$

Table 3 reports results of the DID regression for both treatment definitions. Specification (1) and (4) do not control for market fixed effects and find that banks in a small merging market show a decrease in interest rate of $0.3 \%$ due to a merger while only a decrease of 0.2 $\%$ in the big merging markets. Specifications (2) and (5) do not control for firm fixed effects and there is a decreased effect on deposit prices due to a merger. This shows that bank fixed effects are important. Specifications (3) and (6) are the most preferred specifications where we control for both the fixed effects. In this preferred model specification, a merger in the SMM treatment leads to a $0.2 \%$ drop in the deposit interest rate, although statistically insignificant, while a merger in the BMM treatment leads to a $0.13 \%$ decrease. Coefficients on the control variables show that larger banks with more local branches set lower deposit rates which may indicate some evidence of increase in market power with size. Also, banks in markets with a greater number of banks seem to set larger deposit rates due to increased competition, everything else being equal. The impact of mergers on prices is stronger for the BMM treatment as compared to the SMM treatment, which seems intuitive are a larger number of branches are merged in the BMM treatment.

I perform two robustness tests to verify the above findings of the DID model. First, a continuous version of the DID model is estimated, as a robustness check to the ad-hoc cutoffs of $5 \%$ and $10 \%$, where the treatment dummy $\left(\right.$ Treat $\left._{m}\right)$ is replaced by a continuous variable which measures the maximum fraction of bank branches merged in a market across all years. Continuous specification result is reported in Column (1) of Table 4. It reports that a merger has a significantly negative effect of $0.76 \%$ on deposit rates. Second, an alternative specification is estimated in which only 2 years of post-merger data is taken into account to measure a change in the deposit rates. This alternative specification tests for the fact that the results are not biased because of other events happening in the treatment markets after a merger. Columns (2)-(4) show that the deposit rates drop upto $0.2 \%$ due to a merger. All standard errors are robust and clustered at the market-level.

I compare banks between the treatment and control markets instead of comparing merging and non-merging banks within a market (MSA). One of the possible concerns with my approach might be that including all banks in a treatment market may not accurately capture the effect of a merger on deposit prices. However, a previous study by Prager and Hannan (1998) finds no difference in the change in deposit prices of the merging and rival banks in a market (MSA) after a merger occurs, but report an overall drop in deposit prices in a merging market. This suggests that using both merging and non-merging banks in a

\footnotetext{
${ }^{9} \mathrm{~A}$ time dummy variable to capture year-to-year variation is found to be strongly correlated with the after indicator variable, After ${ }_{m t}$, leading to a bias in our parameter of interest, $\beta_{3}$.
} 
treatment market may not dilute the effect of a merger on prices, on average. Also, comparing banks between treatment and control markets mitigates any concerns of price changes due to a close competitor merging. MSAs are also used by the anti-trust authorities as a definition of a geographic banking market. ${ }^{10}$ An alternative approach can be to use location information to construct a control group of non-merging banks and matching them to a group of merging banks. The advantage here is that both treatment and control groups will have similar market conditions in the before period. My concern with this approach is that branches of most banks are often clustered in specific areas such as marketplaces or shopping districts. The proximity of even a few branches may lead to a close competition among the banks as pricing decisions are made at the firm level. Hence, it may be difficult to find a sufficiently large group of non-merging banks whose all/most branches are far away from all/most branches of the merging banks. ${ }^{11}$ Moreover, if a large bank acquires a small bank, which is usually the case, it is likely that both the merging banks will differ significantly in their sizes, deposit rates and capital asset ratios among other characteristics, making it challenging to define a control group of non-merging banks with similar characteristics.

Overall, we can conclude that mergers led to a decrease in the deposit interest rates. This result supports our finding that cost efficiencies are either weak or absent.

\section{Data Description}

\subsection{Data Sources}

The data used is a panel of commercial banks from 2000 to 2006. Data are taken from three sources. Information on bank ownerships, location of branches and deposit levels is taken from the Summary of Deposits at the Federal Deposit Insurance Corporation (FDIC). The variables in the FDIC data can be divided into three categories: Bank Holding Company (BHC) variables, bank-level variables, and branch variables. Bank holding companies (BHCs) are at the top of this hierarchy, with banks in the middle level and branches at the bottom level. A BHC is a company that controls one or more banks. There are also some small banks that are not registered as a BHC. All BHCs in the U.S. are required to register with the Board of Governors of the Federal Reserve System whereas non-BHC banks can function under the supervision of the Comptroller of the Currency or the Federal Deposit

\footnotetext{
${ }^{10} \mathrm{MSAs}$ are defined as an urban core area plus an adjacent area with close social and economic integration measured by commuting ties.

${ }^{11}$ It may be challenging to find a control group of non-merging banks based on distance for markets having within-market mergers, where the median market has roughly 103 merging bank branches out of a total of 271 branches, on average.
} 


\begin{tabular}{|c|c|c|c|c|c|c|}
\hline & \multicolumn{3}{|c|}{ Small Merger Markets } & \multicolumn{3}{|c|}{ Big Merger Markets } \\
\hline & $(1)$ & $(2)$ & $(3)$ & $(4)$ & $(5)$ & $(6)$ \\
\hline Merger Effect & $\begin{array}{c}-0.00325^{* * *} \\
(0.000845)\end{array}$ & $\begin{array}{l}-0.00120^{* *} \\
(0.000604)\end{array}$ & $\begin{array}{l}-0.00216 \\
(0.00137)\end{array}$ & $\begin{array}{c}-0.00204^{* * *} \\
(0.000603)\end{array}$ & $\begin{array}{c}-0.00115^{* * *} \\
(0.000366)\end{array}$ & $\begin{array}{l}-0.00132^{* *} \\
(0.000612)\end{array}$ \\
\hline \multicolumn{7}{|l|}{ Controls: } \\
\hline Bank Size & $\begin{array}{l}-0.00819 \\
(0.00617)\end{array}$ & $\begin{array}{c}-0.000462^{* * *} \\
(2.95 \mathrm{e}-05)\end{array}$ & $\begin{array}{l}-0.00790 \\
(0.00637)\end{array}$ & $\begin{array}{l}-0.00818 \\
(0.00617)\end{array}$ & $\begin{array}{c}-0.000462^{* * *} \\
(2.95 \mathrm{e}-05)\end{array}$ & $\begin{array}{l}-0.00787 \\
(0.00636)\end{array}$ \\
\hline $\begin{array}{l}\text { \# branches } \\
\text { in a market }\end{array}$ & $\begin{array}{c}-3.26 \mathrm{e}-05 \\
(0.000161)\end{array}$ & $\begin{array}{c}-0.000299^{* * *} \\
(7.45 \mathrm{e}-05)\end{array}$ & $\begin{array}{l}-0.000208 \\
(0.000210)\end{array}$ & $\begin{array}{l}-3.08 \mathrm{e}-05 \\
(0.000163)\end{array}$ & $\begin{array}{c}-0.000299 * * * \\
(7.45 \mathrm{e}-05)\end{array}$ & $\begin{array}{l}-0.000209 \\
(0.000210)\end{array}$ \\
\hline $\begin{array}{l}\text { \# banks } \\
\text { in a market }\end{array}$ & $\begin{array}{c}9.89 \mathrm{e}-06^{* * *} \\
(2.35 \mathrm{e}-06)\end{array}$ & $\begin{array}{c}5.91 \mathrm{e}-05 \\
(4.75 \mathrm{e}-05)\end{array}$ & $\begin{array}{c}9.76 \mathrm{e}-05^{* *} \\
(4.28 \mathrm{e}-05)\end{array}$ & $\begin{array}{c}1.02 \mathrm{e}-05^{* * * *} \\
(2.67 \mathrm{e}-06)\end{array}$ & $\begin{array}{c}5.69 \mathrm{e}-05 \\
(4.71 \mathrm{e}-05)\end{array}$ & $\begin{array}{c}9.53 \mathrm{e}-05^{* *} \\
(4.28 \mathrm{e}-05)\end{array}$ \\
\hline Firm F.E. & Yes & No & Yes & Yes & No & Yes \\
\hline Market F.E. & No & Yes & Yes & No & Yes & Yes \\
\hline Observations & 45,880 & 45,880 & 45,880 & 45,880 & 45,880 & 45,880 \\
\hline R-squared & 0.167 & 0.073 & 0.173 & 0.167 & 0.073 & 0.174 \\
\hline
\end{tabular}

Robust standard errors clustered at the market-level in parentheses $* * * \mathrm{p}<0.01, * * \mathrm{p}<0.05,{ }^{*} \mathrm{p}<0.1$

Table 3: Difference-in-Difference estimation results

\begin{tabular}{|c|c|c|c|c|}
\hline & All years & \multicolumn{3}{|c|}{ Two-years post merger } \\
\hline & Continous & SMM & BMM & Continous \\
\hline & $(1)$ & $(2)$ & $(3)$ & $(4)$ \\
\hline Merger Effect & $\begin{array}{c}-0.00758 * * \\
(0.00326)\end{array}$ & $\begin{array}{c}-0.00242^{*} \\
(0.00126)\end{array}$ & $\begin{array}{l}-0.00146 \\
(0.00375)\end{array}$ & $\begin{array}{l}-0.000486 \\
(0.000729)\end{array}$ \\
\hline Firm F.E. & Yes & Yes & Yes & Yes \\
\hline Market F.E. & Yes & Yes & Yes & Yes \\
\hline Observations & 45,880 & 45,880 & 45,880 & 45,880 \\
\hline R-squared & 0.174 & 0.152 & 0.152 & 0.152 \\
\hline
\end{tabular}

Table 4: Difference-in-Difference: Robustness Tests 
Insurance Corporation. A BHC needs a separate charter for each bank. ${ }^{12}$ For example, Bank of America may have many bank charters and multiple branches across the country but it only has one BHC. In this paper, the decision maker is either a BHC, whenever there is one, otherwise a bank. Roughly $70 \%$ of the decision makers are BHCs in each year. In rest of the paper, banks and BHCs are used interchangeably to refer to the decision maker.

I also use bank level data taken from the Call Reports available at the Federal Reserve Bank of Chicago. Call Reports contain information on the income statement of a bank such as interest expenses on deposits, interest revenues from loans, maintenance fees, equity capital, total employees and wages. Using the hierarchy information in the FDIC data, the bank level data from the Call Reports is aggregated into BHC level data. The interest rate on deposits is calculated as a ratio of interest expenses to total deposits. Similarly, the interest rate on loans is calculated as a ratio of interest revenue to total loans.

Data on demographic information such as population and income is taken from the Bureau of Economic Analysis website.

\begin{tabular}{|c|c|}
\hline Year & No. of BHC/Banks \\
\hline 2000 & 4,351 \\
\hline 2001 & 4,287 \\
\hline 2002 & 4,289 \\
\hline 2003 & 4,240 \\
\hline 2004 & 4,194 \\
\hline 2005 & 4,188 \\
\hline 2006 & 4,227 \\
\hline
\end{tabular}

Table 5: Total number of BHCs and banks from 2000 to 2006.

\subsection{Market and Data Summary}

A market is defined as a Metropolitan Statistical Area (MSA). Antitrust analysis has relied on the definition of a banking market at the MSA level. Using data from the Survey of Consumer Finances, Amel and Starr-McCluer (2001) find that households obtain 90\% of the checking accounts, savings accounts and certificates of deposits within the local market. Kwast, Starr-McCluer and Wolken (1997) find that over 94\% of the small businesses use a local depository institution. Hence, we can safely assume that consumers residing in one market don't travel to other markets for opening their deposit account.

\footnotetext{
${ }^{12}$ Becoming a bank holding company makes it easier for the firm to raise capital than as a traditional bank. The holding company can assume debt of shareholders on a tax free basis, borrow money, acquire other banks and non-bank entities more easily, and issue stock with greater regulatory ease. The downside includes responding to additional regulatory authorities.
} 
Table 5 shows a downward trend in the number of banks over time highlighting consolidation in the industry. There are $344 \mathrm{MSAs}$ in the panel. The average number of BHCs in a market is 48. The smallest number of BHCs in a market (Hinesville, GA) is 4 from 2000-2005, while the market with the most BHCs, Chicago-Naperville-Elgin, IL-IN-WI, had 248 in 2001.

\begin{tabular}{|c|c|c|c|}
\hline $\begin{array}{c}\text { Size } \\
\text { \# branches) }\end{array}$ & $\begin{array}{c}\text { Number of BHCs } \\
\text { (all years combined) }\end{array}$ & $\begin{array}{c}\text { Total obs. } \\
\text { (BHC-market-year) }\end{array}$ & $\begin{array}{c}\text { Average assets per bank } \\
\text { (million \$'s) }\end{array}$ \\
\hline 1 & 2,343 & 8,680 & 165 \\
\hline $2-5$ & 3,052 & 15,385 & 278 \\
\hline $6-50$ & 1,573 & 14,095 & 1,386 \\
\hline $51-500$ & 142 & 7,491 & 26,800 \\
\hline $501+$ & 25 & 7,586 & 328,000 \\
\hline Total & 5,857 & 53,237 & 51,000 \\
\hline
\end{tabular}

Table 6: Size Distribution

Table 6 provides a size distribution which is dis-proportionately skewed towards smaller banks. These small banks are mostly from the pre Riegle-Neal era and they have been common acquisition targets after deregulation when larger banks entered a market by merger. This led banks to grow in size and the number of multi-market banks also increased. Cohen and Mazzeo (2007) treat single and multi-market banks separately to assess competition among retail depository institutions in rural markets. Ramiro (2009) finds that there are significant revenue and cost differences between single and multi-market banks. Motivated by this, we distinguish between small and large banks in the construction of the cost function. The cost function in this paper depends on the total size, measured by the number of branches in the network, and concavity of this function gives us a measure of the cost efficiencies.

The cut-off of small versus large banks is chosen at 300 branches $(\log (300) \approx 5.7)$ using the scatter-plot in figure 1 . There are 43 banks above this cut-off each year on an average. We provide robustness to this ad-hoc assumption by estimating the model separately with a size cut-off of 50 and 500 branches. I discuss the rationale behind the size cut-off and robustness test results in appendix A. It is also important to separate the large banks from a policy standpoint as one of the objectives of the recent Dodd-Frank act was to immunize the economy from the failing of such large banks. ${ }^{13}$

Overall, there are two points worth noting for the model building. First, the data provides

\footnotetext{
${ }^{13}$ The stated aim of the Dodd-Frank legislation is: To promote the financial stability of the United States by improving accountability and transparency in the financial system, to end "too big to fail", to protect the American taxpayer by ending bailouts, to protect consumers from abusive financial services practices, and for other purposes.
} 


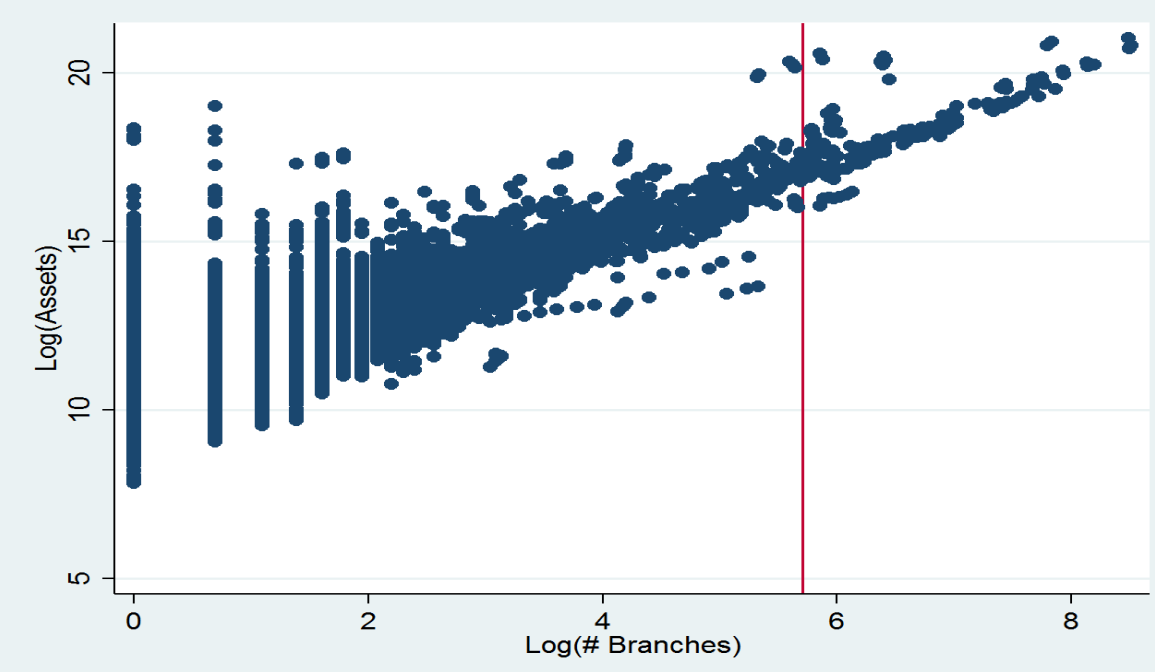

Figure 1: Scatterplot between $\log$ (Assets) and $\log$ (branches). Each data point represents a firm (bank or BHC) in an year.

preliminary evidence of market power supported by findings in existing literature. I take that into account by developing a model where banks competitively collect deposits. Second, there is a need to distinguish between small and large banks in their technology. I address this issue by distinguishing between the small and large banks in the cost function.

\section{Empirical Model of Consumer Demand and Firm Choice}

I develop a model of consumer behavior and firm choice. Consumers choose banks for their deposits to maximize utility. Their utility depends upon the returns on deposits, account maintenance charges, security from bank failure and convenience of availing banking services. Banks choose network of branches, equity capital and deposit interest rate in a three-stage game to maximize profits. The model has local market competition as the source of market power. This model will be used to quantify cost efficiencies.

\subsection{Consumer Demand}

Consumers choose a bank for deposit services based upon the bank's characteristics. Consumer $i$ 's utility from deposit services of bank $j$ in market $m$ and year $t$ is: 


$$
U_{i j m t}=\theta_{1} P_{j t}^{d}+\theta_{2} d_{j m t}+\theta_{3}\left(\frac{k_{j t}}{n_{j t}}\right)+\theta_{4} \log \left(n_{j t}+1\right)+\theta_{5} G D_{j t}+\theta_{6}+\xi_{j m t}+\epsilon_{i j m t},
$$

where $P_{j t}^{d}$ is the deposit price and $d_{j m t}$ is the branch density. Deposit price of a bank is measured by the difference between deposit interest rate and account maintenance fees paid by a depositor. ${ }^{14}$ Branch density is defined as the ratio of the number of branches in a market $m$ of bank $j$ to total income (a measure of market size) in the market $m$ in year $t .{ }^{15}$ The consumers have a preference for branch density because they incur a disutility from distance traveled for their deposit services, which was most recently shown by Ho and Ishii (2010). Capital-size ratio, $\left(\frac{k_{j t}}{n_{j t}}\right)$, is the ratio of equity capital $\left(k_{j t}\right)$ to the total number of bank branches $\left(n_{j t}\right)$ is used to measure safety of a bank since equity is a bank's cushion against losses. This ratio measures differences in attitudes towards risk between insured and uninsured depositors as only uninsured depositors have an incentive to monitor a bank. ${ }^{16}$ Refer to the Appendix E for descriptive evidence on the equity capital.

I allow for the bank's size $\left(n_{j t}\right)$ to enter the consumer utility function logarithmically since the size distribution is highly skewed. Consumers' utility depends upon a bank's size for two reasons. First, larger banks can be perceived safer as compared to the smaller banks with respect to the bankruptcy risk. This perception can develop by observing government bailouts of larger banks in the past. Second, consumers who travel a lot will prefer a bank with more branches. ${ }^{17}$ Geographic dispersion $\left(G D_{j t}\right)$ is measured by the number of markets a bank is present in a particular year. This variable accounts for consumers' preference for convenience to access banking services as well as safety of a bank beyond the size of the branch network. Although, I am using three variables (local branch density, total number of branches and the dispersion of branches) to incorporate the effect of the geographic location of bank branches on consumer demand, I acknowledge that this is done in an indirect, reduced form way to reduce computational burden.

Unobserved bank-market quality is denoted by $\xi_{j m t}$ which includes characteristics like the quality of the training of the customer service employees and reputation of a bank. Also, $\xi_{j m t}$ will measure the firm-market fixed effects that are not captured by the observed

\footnotetext{
${ }^{14}$ Account maintenance fees includes fees charged by the bank to maintain a deposit account, fees charged for failing to maintain specified minimum deposit balances, fees charged for dormant accounts, fees charged for processing of checks against insufficient funds and other service charges on deposit accounts. Account maintenance fees is normalized by total deposits collected by the bank.

${ }^{15}$ Using population as a measure of market size provides similar results.

${ }^{16}$ The capital-asset ratio which banks use as a signal for safety to depositors is proxied by $\left(\frac{k_{j t}}{n_{j t}}\right)$. If I use capital-asset ratio instead of $\frac{k_{j t}}{n_{j t}}$, it would make the market share equation endogenous to solving an implicit integral equation (with no closed form solution), as in equilibrium: assets=deposits+capital. This makes the level of demand of deposits a function of deposits itself in the integral equation.

${ }^{17}$ Since I don't have data on the number of ATM machines, total number of branches acts as a proxy for it. I am making the assumption that number of branches and number of ATMs are positively correlated.
} 
variables. Measurement error is denoted by $\epsilon_{i j m t}$ which is assumed to be type- 1 extreme value distributed.

The outside option $(\mathrm{j}=0)$ to saving money in a commercial bank is using a thrift or a credit union, or having no account at all. ${ }^{18}$ The utility from the outside option is normalized to be zero.

Market share of a bank is calculated as the total deposits of a bank in a market divided by the total income in that market. ${ }^{19}$ Suppose there are $j=1,2, \ldots, J$ banks in a market $m$. Then the mean utility of a bank $j, \delta_{j m t}$, can be defined as,

$$
\delta_{j m t}=\theta_{1} P_{j t}^{d}+\theta_{2} d_{j m t}+\theta_{3}\left(\frac{k_{j t}}{n_{j t}}\right)+\theta_{4} \log \left(n_{j t}+1\right)+\theta_{5} G D_{j t}+\theta_{6}+\xi_{j m t} .
$$

Using the logit error assumption on $\epsilon_{i j m t}$ and integrating over all depositors, I define the market share, $s_{j m t}$, as

$$
s_{j m t}=\frac{\exp \left(\delta_{j m t}\right)}{1+\sum_{k=1}^{J} \exp \left(\delta_{k m t}\right)},
$$

\subsection{Supply side}

Banks generate revenues from loans and incur costs on interest expenses on deposits, equity capital, labor, and physical capital expenditures. A bank's maximization problem is

$$
\begin{array}{r}
\max _{n_{j t}, k_{j t}, P_{j t}^{d}} \Pi_{j t} \\
\text { s.t. } \quad \Pi_{j t}=L_{j t} P_{j t}^{l}-\sum_{m} D_{m t} s_{j m t}(\theta) P_{j t}^{d}-C\left(n_{j t}, k_{j t}\right) \\
L_{j t} \leq \sum_{m} D_{m t} s_{j m t}(\theta)+k_{j t} \\
\quad G\left(k_{j t}, L_{j t}\right) \geq \Delta,
\end{array}
$$

where $L_{j t}$ are the total assets of a bank, $P_{j t}^{l}$ is the average interest rate on assets, $D_{m t}$ denotes total deposits in a market and $s_{j m t}(\theta)$ is the market share of bank $j$. Deposit price of a bank (deposit interest rate - account fees), $P_{j t}^{d}$, is set at the firm level and is same for all markets. This national pricing assumption is consistent with the studies of Radecki (1998) and Hannan and Prager (2004) which show evidence of multi-market banks setting uniform interest rates throughout the area they serve or at least across large geographical regions. $k_{j t}$

\footnotetext{
${ }^{18}$ According to Amel and Starr-McCluer (2001), 98\% of households use a depository institution as of 1998. Thrifts and credit unions comprise less than $6 \%$ in terms of US deposits.

${ }^{19}$ An alternative would be to define market shares in terms of bank accounts. The data on accounts is not available by market but is at the firm-level. Dick (2002) defines market shares in terms of accounts rather than deposits by proportionally allocating the total accounts of a bank to each market. She found that results are robust to this alternative definition.
} 
is the equity capital of a bank i.e. bank's own money at stake. The interest rate on assets, $P_{j t}^{l}$, is allowed to be correlated with $\xi_{j m t} .{ }^{20}$ This is important as a bank with high reputation (or high advertising expenditure) is likely to offer loans with higher interest rates.

The cost, $C\left(n_{j t}, k_{j t}\right)$, consists of three components: labor cost, physical capital cost and the cost of raising equity capital. The labor and physical capital cost incurred by a bank is for loan services, deposit services, advertising expenses and risk management. I assume this cost to be a function of the number of branches $\left(n_{j t}\right)$. Note that the cost function doesn't depend on the location of branches. It is intuitive to think that a branch in a bigger market should have higher costs compared to one in a smaller market or their may be economies of density. Although this is true to some extent, the objective of this paper is to find scale efficiencies in the industry as a whole so I abstract away from this variation. These firm level efficiencies are realized by a reduction in expenses which are common across many markets such as advertising expenditures and risk management expenses. The network effects are accounted through the demand side in the profit function.

The first constraint in the bank profit maximization captures feasibility i.e. total value of loans is equal to the sum of deposits competitively collected by a bank plus the equity capital. Call Reports data on loan information is consolidated at the firm-level without any market-wise breakup. This lack of information makes it infeasible to model the competition on the loan side. Hence, I abstract away from modeling the loan interest rate and assume it is given before the start of the game. However, I am able to model the quantity of loans due to the inclusion of equity capital in the framework.

The second constraint in the bank profit maximization is a regulation constraint. As per the guidelines of the Board of Governers of Federal Reserve Bank, all chartered banks in the U.S. should have a capital-asset ratio above a threshold. In practice, all banks are well above the limit, hence this constraint never binds in the data. ${ }^{21}$

Apart from the regulation constraint, there are two other roles for equity capital. First, it is a source of funding for loans as an alternative to deposits. Hence, labor cost and physical capital cost spent to collect deposits are affected by the level of equity capital. So failing to condition on equity capital can bias the cost parameters. Second, banks use equity capital as a signal of safety to uninsured depositors. The correlation coefficient between $\log$ (Capital Asset Ratio) and $\log ($ Size) is -0.16 (significant at 1\%). This suggests some evidence that

\footnotetext{
${ }^{20}$ Hence, $P_{j t}^{l}$ is not used as an instrument in the demand estimation.

${ }^{21}$ As per the guidelines of Board of Governors of Federal Reserve Bank, all chartered banks in US have to satisfy three constraints: (1) Tier 1 capital / Risk-adjusted assets $>6 \%$ (2) Total capital / Risk-adjusted assets $>10 \%$ (3) Tier 1 capital / Average total consolidated assets $>5 \%$. More than $99 \%$ of the banks are above these constraints. In the data, $10^{t h}$ percentile for these three ratios are $9.6 \%, 10.8 \%$ and $7.2 \%$ respectively.
} 
larger banks need to signal less about their safety.

I assume a quadratic spline functional form for the bank cost function,

$$
\begin{gathered}
C\left(n_{j t}, k_{j t}\right)=\beta_{1} n_{j t}+\beta_{2} n_{j t}^{2}+\beta_{3} I\left(n_{j t}>X\right)\left(n_{j t}-X\right)^{2}+\left[\beta_{4}^{S} I\left(n_{j t} \leq X\right)+\beta_{4}^{L} I\left(n_{j t}>\right.\right. \\
X)] k_{j t}+\gamma_{j t}+\nu_{j t, n_{j t}}
\end{gathered}
$$

where $\gamma_{j t}$ is the bank level productivity shock unobserved to the researcher but observed

by the bank. The measurement error or specification error is denoted by $\nu_{j t, n_{j t}}{ }^{22}$ The parameter $\beta_{3}$ applies for large banks $\left(n_{j t}>X\right)$ only, where $\mathrm{X}$ is the size cut-off between small and large banks. For small banks, the sign of $\beta_{2}$ will determine the presence or absence of cost efficiencies. For large banks, both $\beta_{2}$ and $\beta_{3}$ measure concavity of the cost function. The parameters $\beta_{4}^{S}$ and $\beta_{4}^{L}$ measure the interest rate paid on equity capital by small and large banks, respectively. Any difference in the cost of external funding between small and large banks will be captured by this parameter.

Using the demand and supply side of the model discussed above, I also simulate and measure the market power and cost efficiency trade-off that will be relevant to evaluating a bank merger. Market power will be measured as the difference in profits between the merged entity at new prices and the two merging banks at pre-merger prices. The profit of the merged entity will include the joint effect of market power and quality-effects (other demand factors). I isolate both the effects to understand the different forces at work. Cost efficiencies are measured as the difference in cost expenditure between the merged entity and the two merging banks. I also quantify the change in consumer welfare due to a merger.

In equilibrium, the profit function of a bank can be simplified by substituting the feasibility constraint at equality (assets=liabilities) and using the parametric cost function,

$$
\begin{array}{r}
\Pi_{j t}=\sum_{m} D_{m} s_{j m t}(\theta)\left(P_{j t}^{l}-P_{j t}^{d}\right) \\
+P_{j t}^{l} k_{j}-\beta_{1} n_{j t}-\beta_{2} n_{j t}^{2}-\beta_{3} I\left(n_{j t}>X\right)\left(n_{j t}-X\right)^{2} \\
-\left[\beta_{4}^{S} I\left(n_{j t} \leq X\right)+\beta_{4}^{L} I\left(n_{j t}>X\right)\right] k_{j t}+\gamma_{j t}+\nu_{j t, n_{j t}} .
\end{array}
$$

\subsection{Timing of the Firm Choices}

There are the three stages in the game between banks. In the first stage, banks choose the network of branches $\left(n_{j t}\right)$. This decision is made simultaneously by all banks. In the second stage, banks choose their equity capital $\left(k_{j t}\right)$. In the third stage, banks compete for deposits in a Bertrand competition and choose interest rates $\left(P_{j t}^{d}\right)$.

\footnotetext{
${ }^{22}$ This error term is similar to the non-structural error term in Pakes, Porter, Ho and Ishii (2015).
} 
The stage game set-up in my paper is similar to one in Ishii (2008) which focuses on finding effects of ATM surcharges on competition and welfare. Although the objective and data used in my paper is different from hers, our studies also differs methodologically in two key areas. First, quantity of loans is endogenous in my paper and is equal to sum of deposits and equity capital. In my model, equity capital is a choice variable and deposits are determined in a Bertrand competition. Ishii's paper abstracts away from the loan side. Second, in my model equity capital appears both on the demand side as well as the cost side. Uninsured depositors get higher utility from increased equity capital and banks have to incur a cost to raise equity capital from the investors. This additional step makes my model a three stage game instead of a two-stage game as in Ishii (2008). Ishii's paper abstracts away from liabilities other than deposits. More recently, Kuehn (2014) studies spillovers in banking using a similar methodology.

\section{Estimation}

The model is estimated using backward induction. In the first stage, demand parameters are estimated. The second stage involves estimation of the cost parameter $\left(\beta_{4}^{S}\right.$ and $\left.\beta_{4}^{L}\right)$ on equity capital. In the third stage, cost parameters related to the network structure are obtained.

\subsection{First Stage: Demand Estimation}

Demand parameters are estimated using demand-side and supply-side moments jointly.

In the final stage of the game, banks' compete for deposits and set their deposit prices nationally. Under this assumption, the first order condition w.r.t. $P_{j t}^{d}$ is

$$
\sum_{m} D_{m t} \frac{\partial s_{j m t}(\theta)}{\partial P_{j t}^{d}}\left(P_{j t}^{l}-P_{j t}^{d}\right)-\sum_{m} D_{m t} s_{j m t}(\theta)=0 \quad \forall j t
$$

The first order condition above represents a trade-off: an increase in the deposit interest rate will increase expenditure on all the existing deposits but it will also increase the market share of a bank for deposits and hence increases the revenue from loans. Using the fact that a consumer's utility has a logit error term, I can write the slope of the market share function w.r.t. price as $\frac{\partial s_{j m t}(\theta)}{\partial P_{j t}^{d}}=\theta_{1} s_{j m t}\left(1-s_{j m t}\right)$. Substituting this into the above first order condition I get,

$$
M_{j t}(\theta) \equiv \sum_{m} D_{m t} s_{j m t}\left[\theta_{1}\left(1-s_{j m t}\right)\left(P_{j t}^{l}-P_{j t}^{d}\right)-1\right]=0 \forall j t
$$


This equation forms the basis for the supply side moment. I denote this equation by $M_{j t}(\theta)$.

I need to calculate $\xi_{j m t}(\theta)$ to derive demand side moments. Since a consumer's utility has a logit error, the demand shock can be solved for explicitly as

$$
\xi_{j m t}(\theta)=\ln \left(s_{j m t}\right)-\ln \left(s_{0 m t}\right)-\left(\theta_{1} P_{j t}^{d}+\theta_{2} d_{j m t}++\theta_{3}\left(\frac{k_{j t}}{n_{j t}}\right)+\theta_{4} \log \left(n_{j t}+1\right)+\theta_{5} G D_{j t}+\theta_{6}\right)
$$

where $s_{0 m t}$ is the market share of the outside option.

Demand side moments are derived by finding instruments $\left(Z_{j m t}\right)$ which are un-correlated with bank-market shocks $\left(\xi_{j m t}\right)$ to consumer utility. ${ }^{23}$ Specifically, I need instruments for prices $\left(P_{j t}^{d}\right)$, branch density $\left(d_{j m t}\right)$, size $\left(n_{j t}\right)$, equity capital $\left(k_{j t}\right)$ and geographical dispersion $\left(G D_{j t}\right)$. The correlation between prices and unobserved quality $\left(\xi_{j m t}\right)$ is obvious. Also, it is reasonable to assume that banks' reputation is correlated with its size, dispersion and level of capitalization. Intuitively, a bank with a higher reputation $\left(\xi_{j m t}\right)$, will choose a lower $k_{j t}$ as it needs to signal less about it safety to uninsured depositors. Bank size, branch density and geographic dispersion are instrumented by rival firm characteristics such as number of rival banks in a market, number of rival branches in a market and the size of rival banks. Instrumental variable used for $k_{j t}$ is wages since higher wages correspond to a higher cost of collecting deposits, which would lead firms to choose a higher level of equity capital. Other instruments included in $Z_{j m t}$ are employees per branch and physical capital (cost shifters). The estimating GMM equation is given by,

$$
E\left[\begin{array}{c}
M_{j t}(\theta) \\
Z_{j m t} \xi_{j m t}(\theta)
\end{array}\right]=0
$$

There are 7 moment conditions to estimate 6 parameters. Hence, the system is overidentified. I use the two step GMM procedure with an optimal weighting matrix to estimate the parameters.

\subsection{Second Stage}

In the second stage, the cost parameter on equity capital is estimated using the first order condition (FOC) of a bank's profit function. A bank's equity capital choice is modeled as,

$$
\begin{aligned}
\max _{k_{j t}} \sum_{m} D_{m t} s_{j m t}(\theta)\left(P_{j t}^{l}-P_{j t}^{d}\right)+P_{j t}^{l} k_{j t}-C\left(n_{j t}, k_{j t}\right) \\
\text { s.t. } \quad G\left(k_{j t}, L_{j t}\right) \geq \Delta \\
\sum_{m} D_{m t} s_{j m t}\left[\theta_{1}\left(1-s_{j m t}\right)\left(P_{j t}^{l}-P_{j t}^{d}\right)-1\right]=0 .
\end{aligned}
$$

\footnotetext{
${ }^{23}$ These moments are developed in the spirit of Berry (1994).
} 
The last constraint is the FOC of the Bertrand competition and appears as banks take into account the effect of equity capital choice on the deposit rates chosen in the last stage. The first constraint is the regulation constraint and it is never binding as discussed in section 4.2. Hence, I assume an interior solution to the above maximization problem. On substituting the FOC of $P_{j t}^{d}$ into the profit function,

$$
\Pi_{j t}=\theta_{1}\left(P_{j t}^{l}-P_{j t}^{d}\right)^{2} \sum_{m} D_{m t} s_{j m t}(\theta)\left(1-s_{j m t}(\theta)\right)+P_{j t}^{l} k_{j}-C\left(n_{j t}, k_{j t}\right) .
$$

I can write the FOC of $k_{j t}$ i.e. $\frac{\partial \prod_{j t}}{\partial k_{j t}}=0$ as,

$$
\theta_{1}\left(P_{j t}^{l}-P_{j t}^{d}\right)^{2} \sum_{m} D_{m t}\left[\frac{\partial s_{j m t}}{\partial k_{j t}}-2 s_{j m t} \frac{\partial s_{j m t}}{\partial k_{j t}}\right]+P_{j t}^{l}-\frac{\partial C\left(n_{j t}, k_{j t}\right)}{\partial k_{j t}}=0
$$

Using the logit error assumption in the utility of the consumer, I can simplify $\frac{\partial s_{j m t}}{\partial k_{j t}}$,

$$
\frac{\partial s_{j m t}}{\partial k_{j t}}=\frac{\partial s_{j m t}}{\partial\left(k_{j t} / n_{j t}\right)} \frac{\partial\left(k_{j t} / n_{j t}\right)}{\partial k_{j t}}=\frac{\theta_{3} s_{j m t}\left(1-s_{j m t}\right)}{n_{j t}} .
$$

Note that $n_{j t}$ is treated as a constant in the above equation, because in the second stage when the banks are choosing $k_{j t}$, bank size $\left(n_{j t}\right)$ has already been decided in the first stage. On substituting the expression for $\frac{\partial s_{j m t}}{\partial k_{j t}}$ in the FOC and simplifying,

$$
\theta_{1}\left(P_{j t}^{l}-P_{j t}^{d}\right)^{2} \sum_{m} \frac{\theta_{3} D_{m t} s_{j m t}\left(1-s_{j m t}\right)\left(1-2 s_{j m t}\right)}{n_{j t}}+P_{j t}^{l}=\beta_{4}^{x},
$$

where $x=\{S, L\}$ corresponds to small or large banks. Equation (3) equates marginal revenue from the equity capital to the marginal cost of generating it. The first term on the left corresponds to the marginal revenue from loans funded by the depositors money and the second term is the revenue per dollar of loans that were funded by the equity capital. Parameters $\beta_{4}^{S}$ and $\beta_{4}^{L}$ measure the marginal cost of equity capital for small and large banks respectively. Assuming a mean zero measurement error in the equation (3), parameters $\beta_{4}^{S}$ and $\beta_{4}^{L}$ can be estimated by taking expectation of both sides of the equation (3) as below,

$$
\beta_{4}^{x}=E\left[\theta_{1}\left(P_{j t}^{l}-P_{j t}^{d}\right)^{2} \sum_{m} \frac{\theta_{3} D_{m t} s_{j m t}\left(1-s_{j m t}\right)\left(1-2 s_{j m t}\right)}{n_{j t}}+P_{j t}^{l}\right] .
$$

Note that $\theta_{1}$ and $\theta_{3}$ have already been estimated in the previous stage and everything else in the right hand side of the above estimating equation comes from the data. 


\subsection{Third Stage}

The cost function parameters $\beta_{1}, \beta_{2}$ and $\beta_{3}$ are estimated in this stage. The estimates quantify how the size of a bank affects its cost structure. To this end, I employ the moment inequality estimator proposed by Pakes, Porter, Ho and Ishii (2015) (henceforth PPHI).

Let $I_{j t}$ be the information set of the bank when it chooses the network of branches, $n_{j t}$. The information set $I_{j t}$ consists of $\left\{\xi_{j m t}\right\}_{j, m, t}, P_{j t}^{l}$ and $\gamma_{j t} .^{24}$ The first component of $I_{j t},\left\{\xi_{j m t}\right\}_{j, m, t}$, implies that banks know their level of reputation in each market and that of other banks when making the network choice. This means that a bank deciding to open a branch in a market knows how it will be perceived by the consumers conditional on the other observed variables in their utility function. The second component of $I_{j t}, P_{j t}^{l}$, means that banks know what kind of asset portfolio they will be investing in before deciding where to open branches and how many to open. For example, a lower $P_{j t}^{l}$ implies that a bank is targeting a low-risk low-return portfolio and knowing this it will open branches in markets with more predictable, low-return industrial activity. Another way to rationalize this assumption is to assume that banks are targeting a fixed level of returns on their assets before making any entry decisions. The third component of $I_{j t}$, is the firm level productivity shock, $\gamma_{j t}$, and it corresponds to the management practices and organization structure that are specific to a bank. Banks choose different networks due to the variation in the values of $\xi_{j m t}, P_{j t}^{l}$ and $\gamma_{j t}$. The variation from data comes only through $\xi_{j m t}$ and $P_{j t}^{l}$ as $\gamma_{j t}$ is not observed to us. Although, the bank-market shock, $\xi_{j m t}$, is also unobserved in the data, it is directly calculated from the market share data.

A bank maximizes its expected profits,

$$
\max _{n_{j t}} E\left[\Pi_{j t} \mid I_{j t}\right]
$$

where $\Pi_{j t}$ is the bank-level profits specified in equation (1). A choice of network consists of the number of branches to open and their locations across markets. A bank can choose to have 0,1 or more branches in any market. The expectation arises because of the uncertainty in the bank's observed profit at the time decisions are made. This uncertainty arises due the randomness in the decision of the rival banks, $n_{-j t}$. The randomness could be due to the error term, $\nu_{j t, n_{j t}}$, or due to the presence of mixed strategies.

The location of branches affect the bank revenue through the first term in the profit equation. For example, consider two banks with the same number of branches and similar in all aspects except for the location of the branches. These two banks will collect different

\footnotetext{
${ }^{24}$ The PPHI estimator allows for the possibility of the information set to remain unspecified. So, in principle there could be variables which are unobserved to the econometrician (such as $\gamma_{j t}$ ) but are in $I_{j t}$.
} 
deposits in each market because the market share, $s_{j m t}$, depends on the branch density $\left(d_{j m t}\right)$ in that particular market alongside other variables. This will lead to these two banks having different profits.

Note that the network choice parameters cannot be estimated directly using the maximum likelihood estimation. The possible network choices a bank has in the maximization problem are way too large compared to the number of choices observed in the data. ${ }^{25}$ The PPHI moment inequality method used to estimate the network choice parameters doesn't suffer from this curse of dimensionality.

A necessary condition for any Nash equilibria is that the expected profits from choices observed in the data are greater than any other feasible alternate choice. This forms the basis of the moment inequality estimation method. I construct an expression for the difference in profits for the two policies and then take moments of this differenced profit expression to form the estimating inequalities. Using the profit function for the choice observed in the data $\left(n_{j t}\right)$ and some other alternate policy $\left(n_{j t}^{\prime}\right)$, so that $\left(n_{j t}-n_{j t}^{\prime}=r\right)$, I can difference the profits. The alternate policy, $n_{j t}^{\prime}$, involves addition or subtraction of a fixed number of branches, $r$, from the existing network of a bank. Following is the differenced profit equation,

$$
\begin{array}{r}
\Delta \Pi_{j t}=\Delta Y_{j t}\left(n_{j t}, n_{j t}^{\prime}, n_{-j t}\right)-\beta_{1}\left(n_{j t}-n_{j t}^{\prime}\right)-\beta_{2}\left(n_{j t}^{2}-n_{j t}^{\prime 2}\right) \\
-\beta_{3}\left[I\left(n_{j t}>X\right)\left(n_{j t}-X\right)^{2}-I\left(n_{j t}^{\prime}>X\right)\left(n_{j t}^{\prime}-X\right)^{2}\right]+\nu_{j t, n_{j t}, n_{j t}^{\prime}},
\end{array}
$$

where $\nu_{j t, n_{j t}, n_{j t}^{\prime}}=\nu_{j t, n_{j t}}-\nu_{j t, n_{j t}^{\prime}}$ and $\Delta Y_{j t}\left(n_{j t}, n_{j t}^{\prime}, n_{-j t}\right)$ is the part of the differenced profit function which doesn't contain any parameters to be estimated (because they have already been estimated in the first and second stage). Here is the expression for $\Delta Y_{j t}$,

$$
\begin{aligned}
\Delta Y_{j t}\left(n_{j t}, n_{j t}^{\prime}, n_{-j t}\right) & =\left[\sum_{m} D_{m t} s_{j m t}(\theta)\left(P_{j t}^{l}-P_{j t}^{d}\right)+P_{j t}^{l} k_{j t}-\left[\beta_{4}^{S} I\left(n_{j t} \leq X\right)+\beta_{4}^{L} I\left(n_{j t}>X\right)\right] k_{j t}\right] \\
& -\left[\sum_{m} D_{m t} s_{j m t}^{\prime}(\theta)\left(P_{j t}^{l}-P_{j t}^{\prime d}\right)+P_{j t}^{l} k_{j t}^{\prime}-\left[\beta_{4}^{S} I\left(n_{j t}^{\prime} \leq X\right)+\beta_{4}^{L} I\left(n_{j t}^{\prime}>X\right)\right] k_{j t}^{\prime}\right] .
\end{aligned}
$$

To evaluate $\left(\Delta Y_{j t}\right)$ all the endogenous variables need to be evaluated under the alternate policy: market shares $\left(s_{j m t}^{\prime}\right)$, deposit interest rates $\left(p_{j t}^{\prime}\right)$ and equity capital $\left(k_{j t}^{\prime}\right)$. Market shares and deposit rates are solved as a system of equations using the first order conditions for deposit rates (see equation (2) with the alternative network structure. Equity capital is estimated non-parameterically from the first order condition for equity capital choice (see

\footnotetext{
${ }^{25}$ I observe roughly 4,250 branch network choices each year in the panel data. The possible network choices for 4,250 firms in 343 markets with maximum allowed branches in a market as 20 are: $4250 \times 20^{343}$. It is almost impossible to directly estimate the parameters with such sparse information.
} 
equation (3)) using a third degree polynomial function. ${ }^{26}$

We can simplify the differenced profit function as,

$$
\Delta \Pi_{j t}=\Delta R_{j t}\left(n_{j t}, n_{j t}^{\prime}, n_{-j t}\right)+\nu_{j t, n_{j t}, n_{j t}^{\prime}},
$$

where $\Delta R_{j t}$ is defined as,

$$
\begin{aligned}
\Delta R_{j t}\left(n_{j t}, n_{j t}^{\prime}, n_{-j t}\right) & =\Delta Y_{j t}\left(n_{j t}, n_{j t}^{\prime}, n_{-j t}\right)-\beta_{1}\left(n_{j t}-n_{j t}^{\prime}\right)-\beta_{2}\left(n_{j t}^{2}-n_{j t}^{\prime 2}\right) \\
& -\beta_{3}\left[I\left(n_{j t}>X\right)\left(n_{j t}-X\right)^{2}-I\left(n_{j t}^{\prime}>X\right)\left(n_{j t}^{\prime}-X\right)^{2}\right] .
\end{aligned}
$$

Using the above notation a moment function can be formulated as,

$$
S(\beta)=E\left[h\left(n_{j t}^{\prime} ; n_{j t}, I_{j t}\right) \Delta R_{j t}\left(n_{j t}, n_{j t}^{\prime}, n_{-j t}\right)\right]
$$

where $h\left(n_{j t}^{\prime} ; n_{j t}, I_{j t}\right)$ is the weighting function defined below using instruments $z_{j t}$,

$h\left(n_{j t}^{\prime} ; n_{j t}, I_{j t}\right)= \begin{cases}g\left(z_{j t}\right) & \text { if } n_{j t}-n_{j t}^{\prime}=r \\ 0 & \text { otherwise }\end{cases}$

where $z_{j t} \in I_{j t}$ are demand shifters such as market population and income which are independent of the cost shocks. Refer to the appendix for the details on satisfaction of the sufficiency conditions of the PPHI estimator.

Intuitively, we want parameters that satisfy $S(\beta) \geq 0$. The dimension of the moment function is $\operatorname{dim}(h) \times \operatorname{dim}\left(\Delta R_{j t}\right)$ i.e. we can have more moment restrictions if there are more weighting functions or more alternate policies. Since banks are interacting agents in a particular market, I make use of this by forming the sample analog of the moment by averaging over banks in a market, followed by averaging over all the markets: ${ }^{27}$

$$
s(\beta)=\frac{1}{M} \sum_{m} \frac{1}{J_{m}} \sum_{j_{m}} h\left(n_{j t}^{\prime} ; n_{j t}, I_{j t}\right) \Delta R_{j t}\left(n_{j t}, n_{j t}^{\prime}, n_{-j t}\right) .
$$

The following equation forms the basis for estimation,

$$
\hat{\boldsymbol{\beta}}=\left\{\beta: \beta \in \underset{\beta}{\arg \min }\left\|(s(\beta))_{-}\right\|\right\}
$$

\footnotetext{
${ }^{26}$ An alternate way to predict equity capital for alternate market structures is to use the FOC in equation (3). This method leads to a large system of simultaneous non-linear equations where the interaction occurs through the market share variable. The number of non-linear simultaneous equations in the system is too large $(\sim 4000)$ for the MATLAB optimization solver to handle. Hence, I decided to use a high order polynomial to predict equity capital where the regressors are derived from the FOC. The $R^{2}$ of this polynomial regression is close to 0.8 .

${ }^{27}$ This idea was previously used by Ishii(2007).
} 
where $(\cdot)_{-}=\min (\cdot, 0)$ and $\hat{\boldsymbol{\beta}}$ is the set of identified parameters. The norm used is $L_{1} \cdot{ }^{28}$

The partial identification of cost parameters comes from the difference in the observed and alternative network structures. The magnitude of the difference between $n_{j t}$ and $n_{j t}^{\prime}$ gives different slopes to each estimating inequality. The variation in the intercept, $\Delta Y_{j t}$, is driven both by the difference in the magnitude and location of branches in networks $n_{j t}$ and $n_{j t}^{\prime}$. A usual concern with the set identification approach is that the identified set may potentially be so large that it is uninformative. In practice, this is taken care of by imposing a large number of moment restrictions. This is the case here.

In the objective function, I use two types of moment conditions. The first set of moment conditions only apply to the small banks. The second set of moment conditions apply to all banks. The first set of moments provides identifying power only for $\beta_{1}$ and $\beta_{2}$. With $\beta_{1}$ and $\beta_{2}$ restricted by the first set of moments, the second set of moments identifies $\beta_{3}$. Also, this choice of moments is important as small banks may behave differently from the large banks.

I use three methods to do inference: PPHI inner and outer confidence interval methods and point-wise generalized moment selection method proposed by Andrews and Soares (2010). In the literature for inference of partially identified models, a distinction is made between constructing a confidence interval for the identified set versus a confidence interval for the true parameter. The first two methods from PPHI fall in the first category in which confidence intervals are for the extreme points of the identified set. Generalized moment selection method lies in the second category where point-wise inference is done. Using generalized moment selection method, I can do inference for a point outside of the estimated set also. The algorithm used for the generalized moment selection inference is summarized in the appendix.

A growing industrial organization literature considers partially identified models using moment inequalities for estimation. Holmes (2011) studies diffusion of Walmart using the PPHI estimator. Ishii (2008) studies the effect of ATM surcharges on competition and welfare using moment inequalities also using the PPHI estimator. Ciliberto and Tamer (2009) study an entry game among airlines using a partially identified model. Ellickson, Houghton and Timmins (2012) use moment inequality method to estimate chain economies in the retail industry.

\subsection{Weighting functions and alternate policies}

The weighting functions, $g\left(z_{j t}\right)$, used for estimation are:

\section{Constant function}

\footnotetext{
${ }^{28}$ Results with $L_{2}$ norm are very similar.
} 
2. (Maximum population (or income) of the markets bank $j$ is present in) - (Mean population (or income) of the markets bank $j$ is present in)

3. (Mean population (or income) of the markets bank $j$ is present in) - (Minimum population (or income) of the markets bank $j$ is present in)

The weighting functions are demand shifters which will be uncorrelated with any unobserved cost components $\left(\gamma_{j t}\right)$.

In principle, any alternative policy will satisfy the inequalities since they correspond to the necessary condition of the Nash equilibrium. In our case, alternate choice of the network of branches has to involve either adding new branches or removing existing branches. Otherwise, if I just change the location of existing branches in the data to form an alternate policy without addition/subtraction of branches, the terms involving parameters to be estimated will vanish (see equation (4)). Policies that involve adding branches help to bound the marginal cost from below. Similarly, policies that involve subtracting branches bound the marginal cost from above. Hence, jointly using these two kind of alternate policies gives us tighter bounds for the cost parameters.

The alternate choice of network used to form moments deviates from the choice in the data only marginally so that the estimated bounds can be tighter. When the alternative policy used $\left(n_{j t}^{\prime}\right)$ only differs marginally from the actual policy $\left(n_{j t}\right)$, we are closer to the trade-off the banks may have faced when making the entry decision. For example, a bank with 100 branches in the data is more likely to have considered the possibility of opening 95 or 105 branches, rather than 50 or 200 branches. Also, since profits are calculated by summing over markets, I don't add up the estimation error in demand parameters in the calculation of $\Delta R(\cdot)$ in equation (5) if I change the policy in the data only marginally. In practice, I use alternate policies with addition and subtraction of 1,2,5 and 10 branches from specified markets. The estimated parameter set didn't change with additional alternate policies using a larger deviation ( \pm 20 branches).

For constructing the alternate network structure, I add/subtract branches only in the markets where banks have the largest presence. In the data, large urban areas see more growth in branching while in the smaller cities the number of branches has been almost stagnant. $^{29}$ This fact suggests that banks are more interested in their choices regarding large markets. So, I create alternate policies that affect larger markets which usually are the markets where a bank has a large presence. ${ }^{30}$

\footnotetext{
${ }^{29}$ Refer to FDIC 2006 FYI bulletin for details.

${ }^{30}$ As a robustness check I estimated the set of parameters using additional alternate policies with addition/subtraction of branches applied to markets where banks had least presence. The estimated parameter set didn't change due to this.
} 
The alternate policies used in the moment conditions that involve all banks are,

1. Adding 1 branch in a market where the bank has its largest presence.

2. Subtracting 1 branch in a market where the bank has its largest presence.

3. Adding 1 branch each in the 5 markets where the bank has its largest presence.

4. Subtracting 1 branch each in the 5 markets where the bank has its largest presence.

5. Adding 1 branch each in the 10 markets where the bank has its largest presence.

6. Subtracting 1 branch each in the 10 markets where the bank has its largest presence.

The alternate policies used in the moment conditions that only involve small banks are,

1. Adding 1 branch in a market where the bank has its largest presence.

2. Subtracting 1 branch in a market where the bank has its largest presence.

3. Adding 1 branch each in the 2 markets where the bank has its largest presence.

4. Subtracting 1 branch each in the 2 markets where the bank has its largest presence.

Some small banks go out of business with alternate policies involving subtraction of branches. Profits of these banks are equated to zero under alternate policies.

\section{Results}

This section is divided in three parts. The first part contains results from the demand estimation. These results show the presence of market power and consumer's preference for local branch density as well as a large network of branches nationwide. The second part contains results from estimation of the cost function parameters that will measure the magnitude of efficiencies and the cost of external funding. The third part presents two analyses (one reduced form and one structural) which show that if market power is not accounted for in the estimation, the parameters in the cost function will be biased.

\subsection{Demand Parameters}

Demand parameters are estimated using demand and supply side moments jointly from the 343 markets observed over seven years. The estimated parameters and respective elasticities are reported in Table 7 . The impact of deposit rate on consumer utility, $\theta_{1}$, is 22.95 
suggesting that consumers prefer high deposit rates. ${ }^{31}$ The parameter on the branch density variable, $\theta_{2}$, is 38.66 implying a dis-utility for the distance traveled by depositors. The effect of capital-size ratio on consumer utility, $\theta_{3}$, is estimated to be 9.22 suggesting that consumers prefer banks which are more capitalized. The impact of size on consumer utility, $\theta_{4}$, is 0.115 and significant suggesting that consumers favor banks with more branches, although their branches may be outside of the market. Parameter $\theta_{4}$ captures both consumers preference for convenience and safety. Consumers may view banks safer because either they are geographically diversified or because of their size. However, the parameter on geographic dispersion, $\theta_{5}$, is insignificant suggesting that degree of dispersion doesn't change consumer utility much after controlling for all the other factors. Heteroskedasticity robust standard errors are reported.

It is important to understand the depositors' preference towards safety. The variables which capture safety of a bank are total number of branches, capital-size ratio and geographic dispersion. Among all the demand parameters, these three can be most varied between insured and uninsured depositors. Of these three variables, capital-size ratio is the one which captures safety alone while the other two are also measures of convenience to access the branches. As the coefficient on the capital-size ratio is positive and significant, it suggests that uninsured depositors are actively monitoring the equity capital of a bank. To my knowledge, this effect of the capitalization level of a bank on consumer utility has not been highlighted in any of the previous studies in the banking literature. ${ }^{32}$

Average elasticities imply that consumers are most responsive to local branch density as compared to total branches, prices and capital structure of a bank. Hence, dis-utility incurred from distance traveled is particularly important in this industry as noted previously by Ho and Ishii (2010). The average interest rate elasticity is 0.25 . The price elasticity lying in the inelastic region may seem problematic but it could be an outcome of consumers valuing location of branches significantly more than the deposit interest rates.

I perform three modifications to the base case as a robustness check which are reported in the Appendix D. First, I estimate the model with both demand and supply moments jointly but without any instrumental variables. Second, I estimate the demand parameters with demand-side moments only, by using instrumental variables. Third, I estimate the demand parameters with demand-side moments only, but without any instrumental variables. I find that ignoring instrumental variables biases the coefficient on branch density variable towards zero and the parameter on capital-size ratio becomes insignificant. This confirms that these

\footnotetext{
${ }^{31}$ All the variables in demand estimation are scaled to be of the same order for numerical stability.

${ }^{32}$ Ideally, if the data of uninsured and insured deposits was separately available from the FDIC summary of deposits data, the demand model could be estimated for each piece of data and parameters could be compared for more insight.
} 


\begin{tabular}{|l|l|l|}
\hline Variables & Coefficient & Avg. Elasticity \\
\hline Price & $\begin{array}{l}22.9517^{* * *} \\
(0.0785)\end{array}$ & 0.2448 \\
\hline Branch Density & $\begin{array}{l}38.6582^{* * *} \\
(0.7426)\end{array}$ & 1.6207 \\
\hline Capital-Size Ratio & $\begin{array}{l}9.2194^{* * *} \\
(3.2042)\end{array}$ & 0.0311 \\
\hline \# Branches & $\begin{array}{l}0.1147^{* *} \\
(0.0499)\end{array}$ & 0.3319 \\
\hline Geog. Dispersion & $\begin{array}{l}-0.0031 \\
(0.0019)\end{array}$ & -0.0502 \\
\hline Constant & $\begin{array}{l}-7.2305^{* * *} \\
(0.0845)\end{array}$ \\
\hline
\end{tabular}

Table 7: Logit Demand Estimation (Robust standard errors are in the parenthesis) *** Significant at $1 \%$ level. ** Significant at $5 \%$ level. * Significant at $10 \%$ level.

product characteristics are not exogenous. Robustness checks also show that using the supply side moments are crucial for identification of the price parameter, $\theta_{1}$.

\subsection{Cost Function Parameters}

The cost parameters are estimated in two stages. In the first stage, I estimate the equity capital parameters $\left(\beta_{4}^{S}\right.$ and $\left.\beta_{4}^{L}\right)$. Subsequently, the parameters related to the cost of branch network $\left(\beta_{1}, \beta_{2}\right.$ and $\left.\beta_{3}\right)$ are estimated using the moment inequality method. The moment inequality estimation would use all parameters estimated in the previous stages.

Table 8 reports estimates on network size. Estimated values of $\beta_{2}$ and $\beta_{3}$ indicates the possibility of equilibria that support economies (negative values) but also dis-economies of scale (positive values). This result holds for smaller as well as larger banks. Unless further model selection criteria are applied, the data does not distinguish between various values contained in the identified set, where each parameter set corresponds to a different equilibrium. Hence, data only provides a weak evidence of the cost efficiencies.

The estimates imply that the average physical capital and labor cost of setting up the first branch is between 1.95 million dollars and 13.80 million dollars $\left(\beta_{1}+\beta_{2}\right)$. For the second branch this cost can increase (or decrease) by 145 (2.6) thousand dollars $\left(2 \beta_{2}\right)$. For each new branch, up to the size of 300 branches this cost changes by a factor proportional to $\beta_{2}$. The gap between the minimum and maximum average cost of a branch increases with size, e.g. a bank with 100 branches will have a per branch cost between 1.82 and 20.98 million dollars 
on an average, while this range for a one branch bank is between 1.95 and 13.80 million dollars. Once we cross the barrier of 300 branches, at the lower end of $\beta_{3}$, with a value of -0.0012 , the large banks will still have a concavity in their cost function. At the upper end of $\beta_{3}$, with a value of 0.0633 the cost function for large banks becomes convex with no cost efficiencies.

The confidence intervals constructed using the PPHI methods and the moment selection method are similar qualitatively, however the PPHI methods produce tighter bounds for most parameters. The confidence interval constructed using moment selection method is uniformly consistent whereas PPHI methods are not. Andrews and Soares (2010) strongly advocate the need for uniform consistency in partially identified models. The wide intervals for $\beta_{2}$ and $\beta_{3}$ suggest that the evidence for cost efficiencies in the U.S. banking industry is weak, at best.

The existing literature on banking scale economies has conflicting findings. Stiroh (2000) used 1991-1997 data to find that the largest bank holding companies have stronger cost efficiencies than the smaller ones. Boyd and Graham (1998) examined the effects of mergers and found evidence of cost efficiency gains for only the smallest banks. The gains disappeared quickly with increases in size and were negative for larger banks. Hughes, Mester, and Moon (2001), Hughes, Lang, Mester, and Moon (1996), Hughes and Mester (1998) find strong cost efficiencies for all banks and the largest banks have slightly more cost efficiencies than rest of the banks.

In my model, I consider explicit demand-side which allows me to account for market power and other factors in consumers' utility. None of the existing studies controlled for market power at the local geographic level while calculating cost efficiencies. These papers measure cost efficiencies as the percentage change in profits/costs with unit change in size (measured by assets). It is possible that the change in profits/costs with size could be due to the lowered interest expenses on deposits (market power). This could be the reason why some of the above studies find strong evidence of cost efficiencies. But once we control for market power, the evidence of cost efficiencies is not present.

The cost parameters on the equity capital are listed in the Table 9. This parameter measures the interest rate on the funds generated from investors. Large banks pay an interest rate of $5.37 \%$ while the smaller banks have to pay a higher rate of $6.84 \%{ }^{33}$ These results support the fact that the larger banks are at an advantage when it comes to external funding. Similar result was reported by Shull and Hanweck (2001), where they find that the top 10 largest banks paid less for funds than smaller banks. Equation (3) is the basis for

\footnotetext{
${ }^{33}$ Accounting for the first stage error in demand estimates doesn't changes the parameters very much. Also, a null hypothesis of equal means is rejected at $\alpha=0.01$.
} 


\begin{tabular}{|c|c|c|c|c|c|c|c|c|}
\hline \multirow{3}{*}{$\frac{\text { Variables }}{\text { \# branches }}$} & \multicolumn{2}{|c|}{ Parameter Values } & \multicolumn{6}{|c|}{$95 \%$ Confidence Interval } \\
\hline & L.B. & U.B. & Innel & C.I. & Oute & C.I. & Moment & Selection \\
\hline & 1.9539 & 13.730 & {$[0.1001$} & 19.125] & {$[1.921$} & 27.399] & {$[0.3908$} & 95.627] \\
\hline \# branches ${ }^{2}$ & -0.0013 & 0.0725 & {$[-0.0018$} & $0.1021]$ & {$[-0.0030$} & $0.1555]$ & {$[-0.0066$} & $0.3629]$ \\
\hline$(\# \text { branches }-\mathrm{X})^{2}$ & -0.0012 & 0.0633 & {$[-0.0795$} & $0.1781]$ & -0.1507 & $0.2649]$ & {$[-0.0063$} & $0.3168]$ \\
\hline
\end{tabular}

Table 8: Cost Function Estimation (in million dollars). $\mathrm{X}$ is the cut-off for large banks.

estimation of the interest rates to raise equity capital. The first component in this equation is driven by the demand side and measures consumers' preference for equity capital and other factors driving market share such as number of branches and geographical dispersion. The second component is simply the interest rate on loans. These interest rates on equity capital seem to be majorly driven by the second component, since mean interest rate on loans is $5.20 \%$ and $6.17 \%$ for large and small banks respectively (null hypothesis of equal means is rejected at $\alpha=0.01$ ). Hence, large banks are on a low return frontier as compared to the small banks and this can be perceived as low risk by the investors leading to a low interest rate for large banks.

\begin{tabular}{|c|c|c|c|}
\hline Variable & Parameter & Value & Std. Error \\
\hline Equity Capital(Small banks) & $\beta_{4}^{S}$ & 0.0684 & 0.0025 \\
\hline Equity Capital(Large banks) & $\beta_{4}^{L}$ & 0.0537 & 0.0001 \\
\hline
\end{tabular}

Table 9: Cost Function Estimation: Equity Capital Parameters

Overall, the demand and cost estimates suggest the presence of market power at the local geographic market level, consumers preference for size, capitalization level of a bank and local branch density and at best a weak evidence of cost efficiencies.

\subsection{Importance of Market Power in Cost Estimation}

I conduct two exercises to assess the relative importance of market power in the estimation of cost parameters. First, I estimate the cost function parameters with a panel regression model using operating cost data from the Call Reports. I compare the estimated cost parameters across two specifications, one with interest expenses as a part of the cost and the other without interest expenses as a cost component. Second, I estimate the structural 
model developed in this paper but without any explicit market-level demand side. I estimate two specifications of this model, one with interest expenses as a part of the profit function and one without it.

\subsubsection{A Panel Regresion Model}

I estimate the quadratic cost function discussed earlier in section 4.2. I compare the estimated cost parameters across two specifications, one with interest expenses as part of the cost (With IE) and the other without including any interest expenses in the cost (Without IE). The specification with interest expenses as a part of the operating cost is similar in spirit to the existing studies which do not control for the market power. If the result in the previous section is reliable, the estimation of cost parameters in the Without IE specification should not show any clear evidence of cost efficiencies.

Specifically, I estimate the following regression model,

$\ln \left(C_{j t}\right)=\beta_{0}+\beta_{1} \ln \left(n_{j t}+1\right)+\beta_{2}\left[\ln \left(n_{j t}+1\right)\right]^{2}+\beta_{3} I\left\{n_{j t}>X\right\}\left[\ln \left(n_{j t}+1-X\right)\right]^{2}+\beta_{4} \log \left(k_{j t}\right)+\nu_{j t}$

where $C_{j t}$ is the operating cost including federal funds, non-interest expenses such as salaries, physical capital (furniture, fixture and equipment) and it may or not include deposit interest expenses depending upon the model specification (With IE or Without IE).

The table 10 reports the estimated parameters. The first two columns show results from a pooled OLS model without any firm-level fixed effects. The Without IE specification shows a reduction in the magnitude of $\beta_{2}$ compared to the specification in the first column. This shows that part of the concavity in the cost function is due to a decrease in interest expenses with size. Large banks do show dis-economies of scale in the With IE specification. The next two columns show results with bank fixed effects included in the regression as dummy variables. The With IE specification shows a presence of cost efficiencies for all banks with $\beta_{2}<0$. However, in the Without IE specification, the cost efficiencies become absent from all banks as both $\beta_{2}$ and $\beta_{3}$ are insignificant. The last two columns show results from a panel random effects model. Again, cost efficiencies become absent as interest expenses as excluded from the operating cost. All specifications include year dummies and the standard errors are clustered at the firm level.

I acknowledge that the above regression model may suffer from an omitted variable bias since the number of branches is an endogenous variable and maybe correlated with unobserved cost shifters. In the production function estimation literature, input choices of labor, material and investment (future capital) are often considered to be correlated to a productivity shock which is unobserved to the researcher. In a similar fashion, we 


\begin{tabular}{|c|c|c|c|c|c|c|}
\hline \multirow[b]{2}{*}{ Parameters } & \multicolumn{2}{|c|}{ OLS } & \multicolumn{2}{|c|}{ Fixed-Effects } & \multicolumn{2}{|c|}{ Random-Effects } \\
\hline & With IE & Without IE & With IE & Without IE & With IE & Without IE \\
\hline \multirow[t]{2}{*}{ \# branches } & $0.306^{* * *}$ & $0.336^{* * *}$ & $0.458^{* * *}$ & $0.411^{* * *}$ & $0.391^{* * *}$ & $0.369^{* * *}$ \\
\hline & $(0.0205)$ & $(0.0240)$ & $(0.0272)$ & $(0.0264)$ & $(0.0169)$ & $(0.0172)$ \\
\hline \multirow[t]{2}{*}{ \# branches ${ }^{2}$} & $-0.0144^{* * *}$ & $-0.00928^{* *}$ & $-0.0289^{* * *}$ & -0.0150 & $-0.0113^{* * *}$ & 0.00275 \\
\hline & $(0.00400)$ & $(0.00447)$ & $(0.00757)$ & $(0.00934)$ & $(0.00370)$ & $(0.00415)$ \\
\hline \multirow[t]{2}{*}{$(\# \text { branches }-X)^{2}$} & $0.0159^{* *}$ & 0.00840 & 0.0144 & 0.00902 & 0.00782 & -0.00136 \\
\hline & $(0.00763)$ & $(0.00844)$ & $(0.00927)$ & $(0.0105)$ & $(0.00696)$ & $(0.00743)$ \\
\hline \multirow[t]{2}{*}{ Equity capital } & $0.724^{* * *}$ & $0.709^{* * *}$ & $0.512^{* * *}$ & $0.484^{* * *}$ & $0.623^{* * *}$ & $0.578^{* * *}$ \\
\hline & $(0.00729)$ & $(0.00894)$ & $(0.0151)$ & $(0.0153)$ & $(0.00812)$ & $(0.00912)$ \\
\hline Observations & 29,775 & 29,774 & 29,775 & 29,774 & 29,775 & 29,774 \\
\hline R-squared & 0.925 & 0.912 & & & & \\
\hline Firm F.E. & No & No & Yes & Yes & Yes & Yes \\
\hline Year F.E. & Yes & Yes & Yes & Yes & Yes & Yes \\
\hline
\end{tabular}

Robust standard errors in parentheses

$* * * \mathrm{p}<0.01,{ }^{*} * \mathrm{p}<0.05,{ }^{*} \mathrm{p}<0.1$

Table 10: The table contains estimated cost parameters for two alternative dependent variables, one with interest expenses (with IE) included and the other without interest expenses (Without IE) as a part of the total operating cost. Standard errors are clustered at the firm level.

may consider the number of branches, $n_{j t}$, in the regression equation (7) to be correlated to an unobserved cost shock (measure of inefficiency). This cost shock can capture the performance of bank employees (labor productivity) and also the efficacy of processes for banking services (technological efficiency) among other factors. If the unobserved cost shock is positively correlated with bank size i.e. large banks incur higher unobserved costs, it will upward bias the regression coefficients measuring the effect of size. The relative difference in the cost parameters between the With IE and Without IE specifications, however, is our object of interest which depends on the correlation between the unobserved cost shock and the interest expenses. These two variables are likely to be negatively correlated as a bank with a higher cost shock may try to compensate for it by reducing the deposit interest rate, everything else being equal. A positive correlation between cost shock and size combined with a negative correlation between cost shock and interest expenses will downward bias the effect of size in the With IE specification. ${ }^{34}$ Also, the high $R^{2}$ in the pooled OLS model suggests that most of the variation in operating cost is already captured by the explanatory variables. Moreover, if the omitted variables are time-invariant and correlated with $n_{j t}$, the

\footnotetext{
${ }^{34}$ The effect on the concavity of the cost function due to the unobserved cost shock is difficult to predict since it is a second order effect.
} 
fixed effect model parameters are still unbiased. ${ }^{35}$

Overall, the results indicate a presence of cost efficiencies when interest expenses are included as a cost component. However, when interest expenses are excluded, the estimation results show either no cost efficiencies or a reduction in them. This indicates that part of the cost efficiencies are driven by a reduction in the deposit interest expenses with size. Hence, controlling for market power is important in estimating the cost parameters.

\subsubsection{Cost Estimation: No Market Level Demand Side}

To analyze the importance of market power, I also estimate the cost parameters structurally without any explicit market-level demand in the model developed earlier. Specifically, I estimate the cost parameters with stages two and three only, of the three-stage game. A bank's optimization problem is,

$$
\begin{aligned}
& \max _{n_{j t}, k_{j t}} \Pi_{j t} \\
& \text { s.t. } \quad \Pi_{j t}=L_{j t} P_{j t}^{l}-D_{j t} P_{j t}^{d}-C\left(n_{j t}, k_{j t}\right) \\
& \\
& L_{j t} \leq D_{j t}+k_{j t} \\
& G\left(k_{j t}, L_{j t}\right) \geq \Delta,
\end{aligned}
$$

where $D_{j t}$ is a bank's total deposit across all markets. I estimate cost parameters in the above setup for two scenarios. In Scenario $1(\mathrm{~S} 1)$, the deposit interest expenses $\left(D_{j t} P_{j t}^{d}\right)$ are kept separate from the cost function as shown above. This allows us to estimate the cost parameters after controlling for the market power effect. This scenario is similar to the one estimated in section 6.2, except that it doesn't account for the location of branches as there is no market-level demand side. In Scenario 2 (S2), the deposit interest expenses are omitted from the profit function, so the estimated cost parameters will implicitly contain the market power effects as well. This Scenario 2 is similar to the studies in the literature which do not account for the market power effects.

In equilibrium, the optimization problem for S1 reduces to,

$$
\max _{n_{j t}, k_{j t}} \Pi_{j t}=\left(P_{j t}^{l}-P_{j t}^{d}\right) D_{j t}+P_{j t}^{l} k_{j t}-C\left(n_{j t}, k_{j t}\right)
$$

The cost function, $C\left(n_{j t}, k_{j t}\right)$, depends only on the number of branches and not on their location, so I can estimate the parameters using a simple first order condition as there is no

\footnotetext{
${ }^{35}$ The Hausman Test chooses the fixed effects panel model as the preferred specification.
} 


\begin{tabular}{|c|c|c|c|c|c|c|}
\hline \multirow[b]{2}{*}{ Parameters } & \multicolumn{2}{|c|}{ Size cutoff $=300$} & \multicolumn{2}{|c|}{ Size cutoff $=100$} & \multicolumn{2}{|c|}{ Size cutoff $=50$} \\
\hline & S1 & $\mathrm{S} 2$ & S1 & $\mathrm{S} 2$ & S1 & $\mathrm{S} 2$ \\
\hline \# branches & $\begin{array}{c}4521.035^{* * *} \\
(1193.752)\end{array}$ & $\begin{array}{c}5505.707^{* * *} \\
(52.545)\end{array}$ & $\begin{array}{l}4518.47^{* * *} \\
(1562.077)\end{array}$ & $\begin{array}{c}5449.056^{* * *} \\
(63.1857)\end{array}$ & $\begin{array}{l}4514.29^{* *} \\
(2162.994)\end{array}$ & $\begin{array}{c}5356.734^{* * *} \\
(82.7850)\end{array}$ \\
\hline \# branches ${ }^{2}$ & $\begin{array}{c}0.9575 \\
(75.9776)\end{array}$ & $\begin{array}{c}12.071^{* * * *} \\
(2.9515)\end{array}$ & $\begin{array}{c}1.2733 \\
(121.328)\end{array}$ & $\begin{array}{c}19.0457^{* * *} \\
(4.4166)\end{array}$ & $\begin{array}{c}1.7569 \\
(190.8677)\end{array}$ & $\begin{array}{c}29.7290^{* * *} \\
(6.8056)\end{array}$ \\
\hline$(\# \text { branches }-\mathrm{X})^{2}$ & $\begin{array}{c}-0.6482 \\
(93.2301)\end{array}$ & $\begin{array}{c}-14.3165^{* * *} \\
(3.696)\end{array}$ & $\begin{array}{c}-0.9030 \\
(129.7853)\end{array}$ & $\begin{array}{c}-19.9453^{* * *} \\
(4.7457)\end{array}$ & $\begin{array}{c}-1.3719 \\
(197.2099)\end{array}$ & $\begin{array}{c}-30.3026^{* * *} \\
(7.0874)\end{array}$ \\
\hline
\end{tabular}

Table 11: Cost function parameters estimated with stage 2 and 3 only. Scenario S1 controls for market power while Scenario S2 doesn't.

curse of dimensionality. The FOC with respect to $n_{j t}$ leads to,

$$
\left(P_{j t}^{l}-P_{j t}^{d}\right) \frac{\partial D_{j t}}{\partial n_{j t}}=\frac{\partial C\left(n_{j t}, k_{j t}\right)}{\partial n_{j t}}=\beta_{1}+2 \beta_{2} n_{j t}+2 \beta_{3}\left(n_{j t}-X\right) I\left\{n_{j t}>X\right\}
$$

The right hand side of the above equation is the marginal cost of a branch and a function of the cost parameters. The left hand side of the FOC represents the marginal revenue of a branch. In the absence of a market-level demand side, I need to make an assumption to quantify $\frac{\partial D_{j t}}{\partial n_{j t}}$, so that I can estimate the cost parameters from the above FOC using GMM. I assume $D_{j t}$ to be polynomial function of $n_{j t} \cdot{ }^{36}$ I use revenue shifters as an instrument to estimate the cost parameters such as loan income and deposit account fees. I use an optimal weighting matrix and the system is exactly identified.

The GMM estimation results are reported in Table 11 for various size cut-offs. A comparison of $\beta_{2}$ and $\beta_{3}$ parameters across Scenarios 1 and 2 show that once market power effects are controlled for in Scenario S1, there are no cost efficiencies. This results is similar for different size cut-offs. Moreover, S2 parameters show that there are economies of scale only for large banks (even with size cut-off=50 branches). This results show that ignoring the market power can cause a bias in the cost parameters.

The simplified model in this section gives us the same result as the moment inequality method, however, we cannot ignore a market-level demand side in our analysis. This is because otherwise identical banks may have different interest expenses due to varying degree of competition in the imperfectly competitive markets. If we ignore the market level demand side, this variation in interest expenses for otherwise similar banks can lead to a bias in the cost parameters.

\footnotetext{
${ }^{36}$ In practice, I assume $D_{j t}$ to be a cubic polynomial of $n_{j t}$. The $R^{2}$ of this regression is around 0.7.
} 
Overall, based upon both the analyses in this section we can conclude that controlling for market power effects is important for quantifying cost parameters.

\section{Merger Simulations}

I use the estimated parameters to simulate actual mergers between banks of different sizes that occurred in 2006 or later. The objective of this exercise is to quantify the shortrun effects of market power, cost efficiencies and quality effects generated by a merger. I analyze these effects by comparing merging banks in the post-merger market structure to the pre-merger one. I also calculate the change in consumer welfare due to a merger. As mergers are a widespread phenomenon in the banking industry and an important driver of consolidation (leading to a size increase), it is important to understand their welfare implications. Although, the merger simulations are more restrictive than the cost estimation, they allow us to compare the relative magnitudes of market power, cost-efficiencies and quality effects unlike the cost estimation procedure.

In the simulations, the branch network of the two chosen banks are merged exogenously. After that all banks including the merged entity choose new equity capital and deposit interest rates. Banks are not allowed to re-optimize their branch network in response to a merger. This is not feasible in the current set-up because we haven't explicitly solved for the network-choice policy function. This can be seen as a drawback of the moment inequality method as we can estimate network choice parameters with fewer assumptions but it doesn't allow us to estimate the corresponding policy function. Hence, the merger analysis in this section captures short-run effects generated by a merger. Use of a panel data for estimating the cost and demand parameters however remedies the absence of long-run effects to some extent. Also, I compute the number of branches a merged entity needs to shut down after a merger for their to be cost efficiencies generated by the merger. Although I am not able to solve the dynamic game where all banks re-choose their branch network, this simple rule gives us some insight into the extent of re-organization a bank needs to undertake post-merger to generate efficiencies in the long-run.

In the following simulations, revenues from loans are split in two categories: loans funded through deposits $\left(\sum_{m} D_{m} s_{j m t}(\theta)\left(P_{j t}^{l}-P_{j t}^{d}\right)\right)$ and loans funded through equity capital $\left(P_{j t}^{l} k_{j t}\right)$. Costs are also split in two categories: operating costs $\left(\beta_{1} n_{j t}+\beta_{2} n_{j t}^{2}+\beta_{3} I\left(n_{j t}>\right.\right.$ $\left.X)\left(n_{j t}-X\right)^{2}\right)$ and cost of raising equity capital $\left(\beta_{4}^{S} k_{j t}\right.$ or $\left.\beta_{4}^{L} k_{j t}\right)$. I cannot identify the bank-level cost shock, $\gamma_{j t}$, under the current assumptions. Hence I am not able to quantify the total change in costs/profits due to a merger, but only the magnitude change in the corresponding categories. 
For the merged bank, the deposit rate in each market decreases and market share increases compared to the pre-merger state. Both of these factors drive up the gains from revenue sources in a merger. The post merger deposit rate has both market power and quality-effects embedded into it as discussed in section 4.2. To isolate market power, I have to separate these two effects. I explain my approach using a simple example. Say, bank 1 and bank 2 merge into a bank 12. Each bank's network and deposit rate are denoted by $n_{i}$ and $p_{i}$ respectively, where $\mathrm{i}=1,2$ or 12 . The merged bank's network, $n_{12}$, is the combined network of bank 1 and bank 2 , while the deposit rate, $p_{12}$, is obtained by re-optimizing prices with the combined network of branches. Let the loan revenues funded through deposits for bank $i$ be denoted by $r\left(p_{i}, n_{i}\right) .{ }^{37} E_{1}$ measures the combined effect of quality-effects and market power by,

$$
E_{1} \equiv r\left(p_{12}, n_{12}\right)-r\left(p_{1}, n_{1}\right)-r\left(p_{2}, n_{2}\right)
$$

To measure the quality-effects component of the total effect, I construct an hypothetical scenario. I assume that both the merging banks, 1 and 2, are present in the economy with each bank having all characteristics of the merged bank except the deposit rate. In this setup, all banks re-optimize prices. ${ }^{38}$ Let the price chosen by the two merging banks be denoted by $p$. This setup will measure the effect on profits without any price effects coming from the reduction of competition. Note that in this hypothetical scenario there is no decrease in the number of players in a market. I quantify quality-effects by measuring,

$$
E_{2} \equiv r\left(p, n_{12}\right)-r\left(p_{1}, n_{1}\right)-r\left(p_{2}, n_{2}\right)
$$

where $r\left(p, n_{12}\right)$ is the revenue of one of the merging banks with the combined network. Finally, to calculate the market power effect, I subtract the equation (8) from the equation (7) $\left(E_{1}-E_{2}\right)$. Using this approach, there is no market power in the markets where the merging banks do not overlap. Antitrust regulators also view that banking markets are local in nature and even large bank mergers are not challenged on competitive grounds if there is no significant overlap in the local markets. ${ }^{39}$ A similar calculation is done for consumer surplus to isolate the market power from the combined effect.

The cost efficiency in a merger between two banks at any particular $\left\{\beta_{1}, \beta_{2}, \beta_{3}\right\}$ is calcu-

\footnotetext{
${ }^{37}$ In the real calculation there are other variables also, but to simplify the exposition, I omit them in this example.

${ }^{38}$ Note that both the merging banks will choose the same price.

${ }^{39} \mathrm{~A}$ merger is usually not challenged on competitive grounds unless they would result in a post-merger HHI value of more than 1800 points and an increase in the index of more than 200 points in the relevant local banking market.
} 
lated as,

$$
\begin{gathered}
C E\left(n_{1}, n_{2}\right) \equiv\left[\beta_{1}\left(n_{1}+n_{2}\right)+\beta_{2}\left(n_{1}+n_{2}\right)^{2}+\beta_{3} I\left(\left(n_{1}+n_{2}\right)>X\right)\left(\left(n_{1}+n_{2}\right)-X\right)^{2}\right] \\
-\left[\beta_{1} n_{1}+\beta_{2} n_{1}^{2}+\beta_{3} I\left(n_{1}>X\right)\left(n_{1}-X\right)^{2}\right]-\left[\beta_{1} n_{2}+\beta_{2} n_{2}^{2}+\beta_{3} I\left(n_{2}>X\right)\left(n_{2}-X\right)^{2}\right] .
\end{gathered}
$$

The first term in $C E\left(n_{1}, n_{2}\right)$ is the operating cost of the merged entity, the second and third terms are operating costs of the two merging banks. I uniformly sample from the identified parameter set and calculate the average operating costs. The concavity (or convexity) in the quadratic spline function determines the level of cost savings for the merged bank. The average operating cost per branch always increases after a merger because the spread of the quadratic parameters $\left(\beta_{2}\right.$ and $\left.\beta_{3}\right)$ is more on the positive side than the negative side. For mergers involving large banks, the increase in operating cost is sometimes higher than the increases in revenue. This could be due to factors other than the operating cost savings which large banks account for while making a merging decision such as dynamic adjustment costs or too-big-to-fail motive. This effect corresponds to a positive productivity shock, $\gamma_{j t}$, to the merged entity in our model.

Cost savings from the equity capital (say for a merger between two large banks) are measured by,

$$
E_{3} \equiv \beta_{4}^{L} k_{12}-\beta_{4}^{L} k_{1}-\beta_{4}^{L} k_{2}
$$

where $k_{12}$ is the equity capital corresponding to the merged bank. The level of equity capital of a bank is strongly correlated with size, hence the merged bank has a higher equity capital than each of the merging banks.

While simulating the mergers, I need to make a choice for the loan rate and the unobserved bank-market shock $\left(\xi_{j m t}\right)$ of the merged entity. I choose the maximum loan-rate and maximum $\xi_{j m t}$ of the two banks for the merged entity. ${ }^{40}$ Using the maximum value for unobserved reputation shock is roughly equivalent to using the unobserved shock of the larger bank. Since the larger bank is usually the acquiring bank, it is reasonable to assume that the reputation of the merged entity is same as that of the acquiring bank.

I simulate two mergers in each of the following three categories: small bank and small bank, small bank and large bank, large bank and large bank. For each category, I choose one merger with more overlapping markets than the other. The difference in the level of

\footnotetext{
${ }^{40}$ Results are qualitatively similar even if I choose the minimum loan rate.
} 
overlap will show us the effect of market power more clearly. For simulating the mergers involving small banks, I chose the ones where the acquired bank size was not too small (at least more than 5 branches). For simulating mergers between two large banks, I pick one regular merger (Regions Bank and Amsouth Bank) and one failing bank merger (Wells Fargo and Wachovia). When Wachovia bank was collapsing in the financial crisis, it was forced by the FDIC to sell itself.

The numbers in the tables below are the difference between the revenue and cost components of the merged entity with joint profit maximization and consolidated numbers of the two banks with pre-merger values.

\begin{tabular}{ccc}
\hline & \$Change(Thousand dollars) & \% Change \\
\cline { 2 - 3 } Change in Revenues (per Branch) & & $49.53 \%$ \\
From deposits (Combined effect) & 614.52 & \\
From deposits (Market Power effect) & 26.18 & $11.74 \%$ \\
From deposits(Quality-effect) & 588.34 & \\
From Equity & 248.04 & $7.67 \%$ \\
\hline Change in Cost (per Branch) & $0.39 \%$ \\
From Operating Cost & 685.49 \\
From Equity & 11.20 & \\
\hline Change in Total Consumer Surplus & -0.0004 & $8 \%$ \\
Change in CS due to Market Power & -0.0009 & 4 \\
\# branches need to be closed for efficiency & & \\
\hline
\end{tabular}

Table 12: Merger Simulation : Cumberland Bank,TN (37 branches in 7 markets) and GreenBank,TN (13 branches in 1 market).

\subsection{Mergers between two small banks}

The first merger simulation in this category is between Cumberland Bank (37 branches in 7 markets) and GreenBank (13 branches in 1 market) which occurred in 2007. Cumberland Bank is headquartered in Franklin,TN and GreenBank was headquartered in Greeneville,TN. Cumberland Bank had a presence in the only market GreenBank was present in. Hence, we can expect market power effects for consumers in the overlapping market. The merged bank generates additional revenue of 614.52 thousand dollars per branch from deposits, of which 26.18 thousand dollars can be attributed to market power and remaining 588.34 thousand dollars to the quality-effects. This shows that there is a preference for local branch density 
and large networks compared to the prices. Operating expenses of the merged bank increases by 685 thousand dollars per branch. This happens because uniform sampling of parameters $\left(\beta_{2}\right.$ and $\beta_{3}$ ) leads to more draws of the positive values compared to the negative values. Price effects seem to be playing a less important role in this merger compared to cost efficiencies. Overall, consumer surplus decreases by a very small amount indicating that the increase in utility from a better quality product is offset by the decreased deposit rates due to market power. The loss in consumer surplus due to market power is 0.09 basis points while the overall loss in consumer surplus is 0.04 basis points. In this setup, consumer surplus is the utility, in interest rate terms, that the consumer receives. If the merged bank, shuts down 4 branches out of the total 50 branches, there will be cost efficiencies generated by the merger.

\begin{tabular}{ccc}
\hline & \$Change(Thousand dollars) & \% Change \\
\cline { 2 - 3 } Change in Revenues (per Branch) & & \\
From deposits (Combined effect) & 592.84 & \\
From deposits (Market Power effect) & 0 & \\
From deposits(Quality-effect) & 592.84 \\
From Equity & 583.92 & \\
\hline Change in Cost (per Branch) & & $5.25 \%$ \\
From Operating Cost & 442.28 \\
From Equity & 7.21 & \\
\hline Change in Total Consumer Surplus & $0.25 \%$ \\
Change in CS due to Market Power & 0 & \\
\# branches need to be closed for efficiency & 2 & $6.9 \%$ \\
\hline
\end{tabular}

Table 13: Merger Simulation : AmericanWest Bank (20 branches in 5 markets) and Far West Bank (9 branches in 2 markets) .

The second merger in this category is between AmericanWest Bank (20 branches in 5 markets) and Far West Bank (9 branches in 2 markets) which occurred in 2007. AmericanWest Bank is headquartered in Spokane, WA and Far West Bank was headquartered in Provo, UT. These banks are local in nature and don't overlap in any of the markets. The merged entity is able to generate an extra 592.84 thousand dollars per branch. There is no market power effect here since there is no overlapping market. Operating costs increase by 442 thousand dollars per branch due to the merger. In this simulation, quality-effects seem important for merger profitability. Overall, consumers gain from this merger as the large quality effects dominate the decrease in deposit rates. The gain in consumer surplus is 0.87 basis points. Also, a closure of two branches post-merger will generate cost-efficiencies for 
the bank.

For both small bank mergers, the increase in revenue from the equity capital is much larger than the cost to raise it. This is driven by the assumption that loan rate of the merged bank is the maximum of the two merging banks whereas the cost to raise equity capital remains the same up to the size threshold.

Overall, in both mergers between the two small banks quality effects play an important role in profitability. Average cost savings calculated using uniform sampling of the set identified parameters generate dis-economies of scale.

\subsection{Mergers between a small bank and a large bank}

The first merger in this category is between Comerica bank (355 branches in 26 markets) and Sterling Bank (41 branches in 3 markets) which occurred in 2011. Comerica bank is headquartered in Dallas, TX and Sterling Bank was headquartered in Houston, TX. These banks overlap in two markets. As a result of the merger, revenues from deposits increase by $20.17 \%$ per branch which translates into an addition 0.82 million dollars per branch. Out of these, only 15 thousand dollars can be attributed to market power. This implies presence of strong quality-effects. Cost inefficiencies are roughly $16 \%$ which in dollar terms are an extra 3.1 million dollars per branch. In this simulation, we can clearly see quality-effects dominating over market power. This happens because market power comes from overlapping markets only while quality effects are generated from all the markets. The drop in the cost of equity capital is due to lower interest rate for bigger banks. Consumer surplus increases by 0.8 basis points indicating that the effect of decreased deposit rates is dominated by the increased size of the bank and an increase in the local branch density in the two overlapping markets. The loss in consumer surplus due to market power is 0.13 basis points. For the merged entity to realize efficiencies, it needs to close approximately $7.8 \%$ of its total branches.

The second merger in this category is between Wells Fargo Bank (2,316 branches in 126 markets) and Greater Bay Bank (41 branches in 5 markets) that occurred in 2008. Wells Fargo Bank is headquartered in San Francisco, CA and Greater Bay Bank was headquartered in Palo Alto, CA. Before the merger, Wells Fargo was present in all the 5 markets where Greater Bay Bank was located. The revenue from loans funded by deposits increases by 543 thousand dollars (10\%) per branch. Out of them, 345.64 thousand dollars can be attributed to market power. Operating costs increase by roughly 5 million dollars (3.56\%) per branch which is much larger as compared to the revenue gains. The market power effects are stronger than the other large-small merger due to a lot of overlapping markets. The overall consumer 
\$ Change(Thousand dollars) \% Change

Change in Revenues (per Branch)

From deposits (Combined effect)

From deposits (Market Power effect)

824.81

$20.17 \%$

From deposits(Quality-effect)

15.12

From Equity

809.69

331.08

$16.38 \%$

\begin{tabular}{ccc}
\hline Change in Cost (per Branch) & & \\
From Operating Cost & $3,104.47$ & $15.86 \%$ \\
From Equity & -29.31 & $-1.2 \%$ \\
& & \\
& 0.0080 & \\
Change in Total Consumer Surplus & -0.0013 & $7.83 \%$ \\
Change in CS due to Market Power & 31 & \\
\# branches need to be closed for efficiency &
\end{tabular}

Table 14: Merger Simulation : Comerica Bank (355 branches in 26 markets) and Sterling Bank (41 branches in 3 markets).

surplus goes up suggesting that the effect of decreased interest rates is less than a better quality product (larger bank and increased branch density in the 5 overlapping markets). The loss in consumer surplus due to market power alone is -3.95 basis points.

For both the mergers in the large-small category the increase in revenue from the equity capital is much more than the cost to raise it. The same reasoning applied to the small-small mergers holds here as well. Also, the number of branches need to be shut down to generate efficiencies is very close to the size of the smaller merging bank.

Overall, the increase in consumer surplus in both the mergers implies that consumers are gaining in both the mergers despite weak efficiencies.

\subsection{Mergers between two large banks}

The first merger in this category is between Regions Bank (958 branches in 85 markets) and Amsouth Bank (561 branches in 44 markets) which occurred in 2006. They overlap in 36 markets. Both Regions Bank and Amsouth Bank are headquartered in Birmingham, AL. The revenue from loans funded by deposits increases by 7.04 million dollars (436\%) per branch while operating costs increases by 45.34 million dollars (96\%) per branch. The extra cost needed seems to not be a deterrent for the mergers possibly due to a large productivity $\left(\gamma_{j t}\right)$ shock. Out of the 7.04 million dollars increase in revenue, 3.31 million dollars can be attributed to market power. This is driven by a big overlap of markets. The total consumer surplus increased by 228 basis points suggesting that the effect of decreased interest rates 
\$ Change(Thousand dollars) \% Change

Change in Revenues (per Branch)

From deposits (Combined effect)

From deposits (Market Power effect)

543.09

$10.17 \%$

From deposits(Quality-effect)

345.64

From Equity

197.45

157.07

$4.57 \%$

\begin{tabular}{ccc}
\hline Change in Cost (per Branch) & & \\
From Operating Cost & 5.070 .58 & $0.97 \%$ \\
From Equity & 33.22 & \\
& & \\
& 0.1509 & \\
Change in Total Consumer Surplus & -0.0395 & $1.70 \%$ \\
Change in CS due to Market Power & 40 & \\
\# branches need to be closed for efficiency &
\end{tabular}

Table 15: Merger Simulation : Wells Fargo Bank (2,316 branches in 126 markets) and Greater Bay Bank (41 branches in 5 markets).

is more than offset by a larger bank with an increase in number of local branches for 36 overlapping markets. Of all the merger simulations presented here, the consumer welfare increases by a maximum amount in this merger. This is driven by a large proportion of overlap in the merging banks' markets combined with a high demand elasticity with respect to the local branch density. Also, for the merged bank to generate efficiencies roughly $28 \%$ of the branches need to be shut down. As the size of a merging bank gets larger, a higher proportion of the branches need to be closed post-merger to generate efficiencies.

The second merger in this category is between Wells Fargo Bank (2,316 branches in 126 markets) and Wachovia Bank (2,769 branches in 100 markets) which occurred in 2008. The merging banks overlapped in only 7 markets. Wachovia bank was headquartered in Charlotte, North Carolina and Wells Fargo Bank is headquartered in San Francisco, CA. This merger took place during the financial crisis and it was a FDIC forced merger. Total consumer surplus went up by 28.7 basis points due to this merger. The amount of network overlap in this merger is less as compared to the Amsouth-Regions bank merger. For this merger to generate cost efficiencies, roughly $30 \%$ of its branches needs to be shut down. For both mergers in this category, the change in revenue and cost from equity capital roughly balance each other.

Also, in a small-small merger, roughly $7 \%-8 \%$ of the total branches need to be closed post-merger, whereas in a large-large merger a considerably larger fraction (27\%-30\%) need 


\begin{tabular}{|c|c|c|}
\hline \multirow[b]{2}{*}{ Change in Revenues (per Branch) } & \$ Change(Thousand dollars) & $\%$ Change \\
\hline & & \multirow{3}{*}{$435.96 \%$} \\
\hline From deposits (Combined effect) & $7,041.68$ & \\
\hline From deposits (Market Power effect) & $3,312.32$ & \\
\hline From deposits(Quality-effect) & $3,729.35$ & \\
\hline From Equity & 421.96 & $20.16 \%$ \\
\hline \multicolumn{3}{|l|}{ Change in Cost (per Branch) } \\
\hline From Operating Cost & $45,343.13$ & $96.49 \%$ \\
\hline From Equity & 363.25 & $13.85 \%$ \\
\hline Change in Total Consumer Surplus & 2.28 & \\
\hline Change in CS due to Market Power & -0.6968 & \\
\hline \# branches need to be closed for efficiency & 421 & $27.72 \%$ \\
\hline
\end{tabular}

Table 16: Merger Simulation : Regions Bank (958 branches in 85 markets) and Amsouth Bank (561 branches in 44 markets).

\begin{tabular}{ccc}
\hline & \$Change(Thousand dollars) & \% Change \\
\cline { 2 - 2 } Change in Revenues (per Branch) & \\
From deposits (Combined effect) & 722.82 & $13.42 \%$ \\
From deposits (Market Power effect) & 86.99 & \\
From deposits(Quality-effect) & 635.82 & \\
From Equity & $1,844.49$ & \\
& & $104 \%$ \\
Change in Cost (per Branch) & $167,634.09$ \\
From Operating Cost & $1,639.40$ & \\
From Equity & & \\
\hline Change in Total Consumer Surplus & 0.2870 \\
Change in CS due to Market Power & -0.0372 & $29.58 \%$ \\
\# branches need to be closed for efficiency & 1,504 & \\
\hline
\end{tabular}

Table 17: Merger Simulation : Wells Fargo Bank(2,316 branches in 126 markets) and Wachovia bank(2,769 branches in 100 markets).

to be closed to generate cost efficiencies.

Overall, out of the 6 simulated mergers, 5 of them report an increase in the consumer welfare alongside dis-economies of scale for banks in the short-run. If cost efficiencies are indeed absent, consumers should be worse-off due to the market power effects, at least in the short-run. However, the marker power effects get dominated by the quality effects (consumers' preference for local branch density, size and equity capital) and this increases the consumer welfare after a merger. 


\section{Conclusion}

This paper quantifies the degree of cost efficiencies in the U.S. banking industry while accounting for market power and other demand synergies. We develop a model of consumer behavior and firm choice where market power is a geographically local phenomenon whereas cost efficiencies are realized at the firm level. We develop a three-stage empirical model in which consumers choose banks for deposit services and banks choose the network of branches, equity capital and deposit rates. To estimate the cost parameters related to the network choice, we use moment inequality methods to address the issue of multiple equilibria and large dimensionality of the choice set.

Demand estimates suggest that consumers prefer banks which are large, more capitalized and have a higher number of local branches. After controlling for market power, the evidence for cost efficiencies is weak, at best, for all banks. This is a contribution to the existing literature which doesn't control for local market power and quality-effects in the calculation of cost efficiencies. We also find that smaller banks are at an disadvantage when it comes to borrowing money from external sources.

Using the estimated parameters, I simulate two mergers in each of the three categories: between two small banks, a small bank and a large bank and between two large banks. Quality effects generated by the size and local branch density of a bank are always stronger than the oligopoly price effects. On an average, cost-efficiencies doesn't play a positive role in merger profitability. Of the six mergers analyzed, five of them generate positive surplus for consumers. This suggests that the consumers benefit more from bigger banks and a higher number of local branches as compared to the negative price effects due to market power.

\section{References}

[1] Victor Aguirregabiria, Robert Clark, and Hui Wang. Diversification of Geographic Risk in Retail Bank Networks: Evidence from Bank Expansion after the Riegle-Neal Act. The RAND Journal of Economics, 47(3):529-572, 2016.

[2] Oktay Akkus, J. Anthony Cookson, and Ali Hortacsu. The Determinants of Bank Mergers: A Revealed Preference Analysis. Management Science, 2016.

[3] Dean F. Amel and J. Nellie Liang. The relationship between entry into banking markets and changes in legal restrictions on entry. The Antitrust Bulletin, 37:631-649, 1992. 
[4] Dean F. Amel and M. Starr-McCluer. Market definition in banking: Recent evidence . Federal Reserve Board Finance and Economics Discussion Series, pages 2001-2016, 2001.

[5] D. Andrews and G. Soares. Inference for Parameters Defined by Moment Inequalities Using Generalized Moment Selection. Econometrica, 78:119-157, 2010.

[6] Azzeddine M Azzam and Emilio Pagoulatos. Testing oligopolistic and oligopsonistic behaviour: an application to the us meat-packing industry. Journal of Agricultural Economics, 41(3):362-370, 1990.

[7] John M Barron, Beck A Taylor, and John R Umbeck. New evidence on price discrimination and retail configuration. Applied Economics Letters, 8(2):135-139, 2001.

[8] Allen Berger, Rebecca Demsetz, and Philip Strahan. The Consolidation of the Financial Services Industry: Causes, Consequences, and Implications for the Future. Journal of Banking and Finance, 23, 1999.

[9] A.N. Berger, G.A. Hanweck, and D.B. Humprey. Competitive viability in banking: Scale, scope, and product mix economies. Journal of Monetary Economics, 20:501-520, 1987.

[10] Steve Berry. Estimating discrete-choice models of product differentiation. The RAND Journal of Economics, 25(2):242-262, 1994.

[11] Severin Borenstein. Selling costs and switching costs: explaining retail gasoline margins. The RAND Journal of Economics, pages 354-369, 1991.

[12] John Boyd and David Runkle. Size and Performance of Banking Firms. Journal of Monetary Economics, 31:47-67, 1993.

[13] John Boyd and Graham Stanley. Consolidation in US Banking. New England Economic Review, 23:113-135, 1998.

[14] Federico Ciliberto and Elie T. Tamer. Market Structure and Multiple Equilibria in the Airline Industry. Econometrica, 77(6):1791-1828, 2009.

[15] Andrew M. Cohen and Michael J. Mazzeo. Market Structure and Competetion among Retail Depository Institutions. The Review of Economics and Statistics, 89(1):60-74, 2007. 
[16] Dean Corbae and Pablo D'Erasmo. A Quantitative Model of Banking Industry Dynamics . Working Paper, 2013.

[17] Astrid Dick. Demand estimation and consumer welfare in the banking industry. Federal Reserve Board Finance and Economics Discussion Series, pages 2002-58, 2002.

[18] Astrid Dick. Demand estimation and consumer welfare in the banking industry. Journal of Banking and Finance, 32:1661-1676, 2008.

[19] Timothy Dunne, Pradeep Kumar, and Mark Roberts. Market Structure and Growth of Banking in Rural Markets. Working Paper, 2012.

[20] Ramiro de Elejalde. Local Entry Decisions in the US Banking Industry. Working Paper, 2009.

[21] Paul Ellickson, Stephanie Houghton, and Christopher Timmins. Estimating Network Economies in Retail Chains: A Revealed Preference Approach. The RAND Journal Of Economics, 44(2):169-193, 2013.

[22] J. Farrell and C. Shapiro. Antitrust Evaluation of Horizontal Mergers: An Economic Alternative to Market Definition. The B.E. Journal of Theoretical Economics, 10(1), 2010.

[23] Timothy Hannan and Robin Prager. Do Substantial Horizontal Mergers Generate Significant Price Effects? Evidence From The Banking Industry. The Journal of Industrial Economics, 46(4):433-452, 1998.

[24] Timothy Hannan and Robin Prager. The competitive implications of multimarket bank branching. Journal of Banking and Finance, 28:1889-1914, 2004.

[25] Justine S Hastings and Richard J Gilbert. Market power, vertical integration and the wholesale price of gasoline. The Journal of Industrial Economics, 53(4):469-492, 2005.

[26] Kate Ho and Joy Ishii. Location and competition in retail banking. International Journal of Industrial Organization, 29(5):537-546, 2011.

[27] Thomas J. Holmes. The Diffusion of Wal-Mart and Economies of Density . Econometrica, 79(1):253-302, 2011.

[28] Joseph Hughes, W. Lang, Loretta Mester, and Choon-Geol Moon. Efficient banking under interstate branching. Journal of Money, Credit, and Banking, 28:1045-1071, 1996. 
[29] Joseph Hughes and Loretta Mester. Bank capitalization and cost: Evidence of scale economies in risk management and signaling. Review of Economics and Statistics, 80:314-325, 1998.

[30] Joseph Hughes, Loretta Mester, and Choon-Geol Moon. Are scale economies in banking elusive or illusive? : Evidence obtained by incorporating capital structure and risktaking into models of bank production. Journal of Banking and Finance, 25(12):2169$2208,2001$.

[31] Joy Ishii. Compatibility, Competition and Investment in Network Industries: ATM Networks in the Banking Industry. Working Paper, 2008.

[32] CS Kim, C Hallahan, Harold Taylor, Gerald Schluter, et al. Market power and costefficiency effects of the market concentration in the us nitrogen fertilizer industry. Economic Research Service, USDA,(202), 2002.

[33] Joseph Kuehn. Spillovers from Entry: The Impact of Bank Branch Network Expansion . Working Paper, 2014.

[34] M. Kwast, M. Starr-McCluer, and J. Wolken. Market definition and the analysis of antitrust in banking. The Antitrust Bulletin, 42:973-995, 1997.

[35] Loretta Mester. Efficient production of financial services: Scale and scope economies. Business Review, pages 15-25, 1987.

[36] Ariel Pakes, Jack Porter, Kate Ho, and Joy Ishii. Moment inequalities and their application. Econometrica, 83(1), 2015.

[37] L.J. Radecki. The expanding geographic reach of retail banking markets . Economic Policy Review, 4:15-34, 1998.

[38] John R Schroeter. Estimating the degree of market power in the beef packing industry. The Review of Economics and Statistics, pages 158-162, 1988.

[39] Bernard Shull and Gerald Hanweck. Bank Mergers in a Deregulated Environment: Promise and Peril. Quorum Books, 2001.

[40] Katerina Simons and Joanna Stavins. Has Antitrust Policy in Banking Become Obsolete? New England Economic Review, 23:13-26, 1998.

[41] Kevin J. Stiroh. How did bank holding companies prosper in the 1990s? Journal of Banking and Finance, 24:1703-1745, 2000. 
[42] Kevin J. Stiroh and Philip E. Strahan. Competitive Dynamics of Deregulation: Evidence from U.S. Banking. Journal of Money, Credit, and Banking, 35(5):801-828, 2003.

[43] Kosuke Uetake and Yasutora Watanabe. Entry by Merger: Estimates from a Two-Sided Matching Model with Externalities. Working Paper, 2012.

[44] Joyce J Wann and Sexton Richard J. Imperfect competition in multiproduct food industries with application to pear processing. American Journal of Agricultural Economics, 74(4):980-990, 1992.

[45] Xiaolan Zhou. Estimation of the Impact of Mergers in the Banking Industry with Historical Data on Mergers . Working Paper, 2008.

\section{Appendices}

\section{A. Robustness to size cut-off}

I distinguish between small and large sized banks in the cost function. In the paper, I present the estimated cost parameters with a size cut-off of 300 branches. I try two alternative cut-offs: 50 branches and 500 branches. Table 18 has descriptive statistics on the three size cut-offs. There is a large difference between the asset size of the small and large banks. Interestingly, in all the three size classifications the median bank in the small category is only present in a single market. Also, the number of banks in the large category is much less than the small category because of the skewed size distribution.

Since the data has a disproportionately greater number of small banks, a larger size cutoff can reduce the number of observations for large banks and may affect the precision of the estimated cost parameter set for the large banks $\left(\beta_{3}\right)$. On the other hand, a smaller size cutoff may not fully capture the conduct of the large banks with nationwide presence. Given this trade-off, the three size cut-offs test for the robustnesss of the estimated parameters. I measure bank sizes on a log scale which range from 0 (one-branch bank) to $8.2(3,626$ branch bank) as shown in Figure 1. One way to define a bank as large is if its size is above the $50^{\text {th }}$ percentile on the log size range, which is roughly in-line with a cutoff of 50 branches $(\log (50)=3.9)$. Although there are 160 banks above this cutoff, it may not accurately capture the conduct of banks with hundreds of nationwide branches. As a robustness check, I increase the cutoff to the $75^{\text {th }}$ percentile, which approximately corresponds to a size cutoff of 500 branches $(\log (500)=6.2)$. However, there are only 25 banks above this size cut-off which may imply a reduced precision in the estimated parameters. Hence, for the main specification, I choose an in-between cutoff of 300 branches. There are 43 banks above this size cut-off with 
each bank having branches in 80 markets, on an average, which suggests that these banks are present in multiple states and are large regional or national banks.

Table 19 and Table 20 contain parameter estimates for the alternative cut-offs. The results look qualitatively similar to the cut-off used in the paper.

\begin{tabular}{|c|c|c|c|}
\hline $\begin{array}{c}\text { Size Categories } \\
\text { \# branches })\end{array}$ & No. of BHCs/banks & $\begin{array}{c}\text { Mean(median)\# markets } \\
\text { a bank is present in }\end{array}$ & $\begin{array}{c}\text { Avg. Assets } \\
\text { (million dollars })\end{array}$ \\
\hline$<50$ & 5735 & $1.97(1)$ & 661 \\
\hline$\geq 50$ & 160 & $55.45(34)$ & 178,000 \\
\hline$<300$ & 5829 & $3.78(1)$ & 2,874 \\
\hline$\geq 300$ & 43 & $80.88(63)$ & 281,000 \\
\hline$<500$ & 5839 & $4.65(1)$ & 4,951 \\
\hline$\geq 500$ & 25 & $92.17(84)$ & 328,000 \\
\hline
\end{tabular}

Table 18: Descriptive statistics for various size cut-offs

\begin{tabular}{|c|c|c|cc|}
\hline Parameters & $\begin{array}{c}\text { Lower } \\
\text { Bound }\end{array}$ & $\begin{array}{c}\text { Upper } \\
\text { Bound }\end{array}$ & $\begin{array}{c}95 \% \text { Confidence Interval } \\
\text { (Generalized Moment Selection) }\end{array}$ \\
\hline \# branches & 1.8715 & 5.8014 & {$\left[\begin{array}{ll}0.3743 & 29.007\end{array}\right]$} \\
\# branches & & -0.0002 & 0.1291 & {$\left[\begin{array}{ll}-0.001 & 0.6457\end{array}\right]$} \\
$(\# \text { branches }-\mathrm{X})^{2}$ & -0.1097 & 0.0781 & {$\left[\begin{array}{ll}-0.5487 & 0.3909\end{array}\right]$} \\
\hline
\end{tabular}

Table 19: Cost Function Estimation (in million dollars). $\mathrm{X}$ is the size cut-off=50 branches.

\begin{tabular}{|c|c|c|cc|}
\hline Parameters & $\begin{array}{c}\text { Lower } \\
\text { Bound }\end{array}$ & $\begin{array}{c}\text { Upper } \\
\text { Bound }\end{array}$ & $\begin{array}{r}\text { 95 \% Confidence Interval } \\
\text { (Generalized Moment Selection) }\end{array}$ \\
\hline \# branches & 1.9663 & 13.730 & {$\left[\begin{array}{ll}0.3932 & 47.152\end{array}\right]$} \\
\# branches ${ }^{2}$ & -0.0002 & 0.0673 & {$\left[\begin{array}{ll}-0.0009 & 0.2801\end{array}\right]$} \\
$(\# \text { branches }-\mathrm{X})^{2}$ & -0.0117 & 0.3934 & {$\left[\begin{array}{ll}-0.0585 & 1.6296\end{array}\right]$} \\
\hline
\end{tabular}

Table 20: Cost Function Estimation (in million dollars). X is the size cut-off $=500$ branches.

\section{B. Sufficiency conditions for PPHI estimator}

The weighting function and errors should satisfy the following two sufficiency conditions to use the PPHI estimator. 
Condition 1: $E\left[\sum_{j t} \sum_{n_{j t}^{\prime}} h\left(n_{j t}^{\prime} ; n_{j t}, I_{j t}\right) \nu_{j t, n_{j t}, n_{j t}^{\prime}}\right] \geq 0$

Condition 2: $E\left[\sum_{j t} \sum_{n_{j t}^{\prime}} h\left(n_{j t}^{\prime} ; n_{j t}, I_{j t}\right) \Delta \gamma_{j t, n_{j t}, n_{j t}^{\prime}}\right] \leq 0$

Using $E\left[\nu_{j t, n_{j t}, n_{j t}^{\prime}} \mid I_{j t}\right]=0$ and since $I_{j t}$ doesn't contain any information about rivals, condition 1 is trivially satisfied.

Condition 2 is also trivially satisfied as $\Delta \gamma_{j t, n_{j t}, n_{j t}^{\prime}}$ equals zero. In my model, the structural error $\gamma_{j t}$ is fixed before the network choice.

\section{Inference using Generalized Moment Selection}

Following steps are used in sequence to calculate the confidence sets using the Andrews and Soares (2010) moment selection method,

1. Form a 3 -dimensional grid of points in $\left\{\beta_{1}, \beta_{2}, \beta_{3}\right\}$ space which extends well beyond the identified set. ${ }^{41}$

2. At each grid point $\beta_{g}$, evaluate the objective function: $\left.Q\left(\beta_{g}\right)=\|{\hat{D_{M}}}^{-1 / 2} s\left(\beta_{g}\right)\right)_{-} \|$, where $\hat{D_{M}}$ is a diagonal matrix with variance of the moments on its diagonal.

3. At each grid point, a critical value is calculated through simulation, $c_{\alpha}\left(\beta_{g}\right)$.

4. If $Q\left(\beta_{g}\right) \leq c_{\alpha}\left(\beta_{g}\right)$, then $\beta_{g}$ is in confidence set.

The calculation of critical value is the most important step in the above method. To compute the critical value, an approximation to the distribution of objective function under the null is simulated. The distribution of the sample moments in the expression of objective function are simulated by a normal with mean zero and variance calculated using the data across markets. Next, of all the simulated moments under the null, only the nearly binding moments at each $\beta_{g}$ enter the expression for simulating the objective function. A moment $k$ is defined to be nearly binding if $\sqrt{M} E\left(s_{k}\left(\beta_{g}\right)\right) / \hat{\sigma}\left(s_{k}\left(\beta_{g}\right)\right)<\sqrt{2 \ln (\ln (M))}$, where the expectation operator is replaced by its sample analog and $\mathrm{M}$ is the total number of markets.

\section{Robustness for demand estimates}

The demand estimates in the paper are calculated using both demand and supply side moments. The Table 21 reports estimation results for the alternative specifications as discussed in the section 6.1.

\footnotetext{
${ }^{41}$ The grid is constructed so that the null hypothesis is rejected at the end points of the grid.
} 


\begin{tabular}{|c|ll|ll|}
\hline \multirow{2}{*}{ Variables } & \multicolumn{2}{|c|}{$\begin{array}{c}\text { Both Demand moments } \\
\text { and Supply moments (X) }\end{array}$} & \multicolumn{2}{c|}{$\begin{array}{c}\text { Demand moments only } \\
\text { (without IV) }\end{array}$} \\
\hline & With IV & Without IV & With IV & Without IV \\
\hline Price & $22.9517^{* * *}$ & $22.9562^{* * *}$ & $51.7500^{* * *}$ & 5.2404 \\
& $(0.0785)$ & $(0.0785)$ & $(15.7974)$ & $(4.4431)$ \\
\hline Branch Density & $38.6582^{* * *}$ & $18.7090^{* * *}$ & $36.4474^{* * *}$ & $18.8217^{* * *}$ \\
& $(0.7426)$ & $(0.2021)$ & $(0.9859)$ & $(0.2048)$ \\
\hline Capital-Size Ratio & $9.2194^{* * *}$ & 0.3617 & $13.6726^{* * *}$ & 0.4146 \\
& $(3.2042)$ & $(0.3145)$ & $(4.9488)$ & $(0.3222)$ \\
\hline \# Branches & $0.1147^{* *}$ & $0.2350^{* * *}$ & $0.3374^{* * *}$ & $0.2127^{* * *}$ \\
& $(0.0499)$ & $(0.0052)$ & $(0.0748)$ & $(0.0077)$ \\
\hline Geog. Dispersion & -0.0031 & -0.0003 & $-0.0112^{* * *}$ & -0.0002 \\
& $(0.0019)$ & $(0.0002)$ & $(0.0024)$ & $(0.0002)$ \\
\hline Constant & $-7.2305^{* * *}$ & $-6.7359^{* * *}$ & $-8.0018^{* * *}$ & $-6.4857^{* * *}$ \\
& $(0.0846)$ & $(0.0119)$ & $(0.2841)$ & $(0.0638)$ \\
\hline
\end{tabular}

Table 21: Logit Demand Estimation (Robust standard errors are in the parenthesis.) *** Significant at $1 \%$ level. ${ }^{* *}$ Significant at $5 \%$ level. $*$ Significant at $10 \%$ level.

\section{E. Equity capital descriptive statistics}

This section reports basic correlations of equity capital with deposits, bank size and market shares. The level of equity capital is positively correlated to the total number of branches of a bank and to the total deposits of a bank. Larger banks have more assets and hence need a higher level of equity capital to satisfy the regulation constraints. Figure 2 and Figure 3 show the scatter plots with log of equity capital on the y-axis and log of deposits and log of size on the x-axis. Positive correlation in the data strengthens our intuition about the role of equity capital in the model.

Next, we want to explore the relationship between market share and equity capital. To counter the size effect, I look at the correlation between log of market share and the log of the ratio of equity capital to the total number of branches. Figure 4 shows the scatter plot with a significant positive correlation between the two. This provides a preliminary evidence that a depositor's utility may depend on the capitalization level of a bank.

\section{F. Difference in difference: treatment and control group similarity}

Table 22 compares some key features of the control and treatment markets in the before period. The average deposit and loan rates in the before period are similar between the two groups for both the treatments: small merger markets and big merger markets. Median bank size is also comparable between the two groups. Equity capital to asset ratio averaged over all 


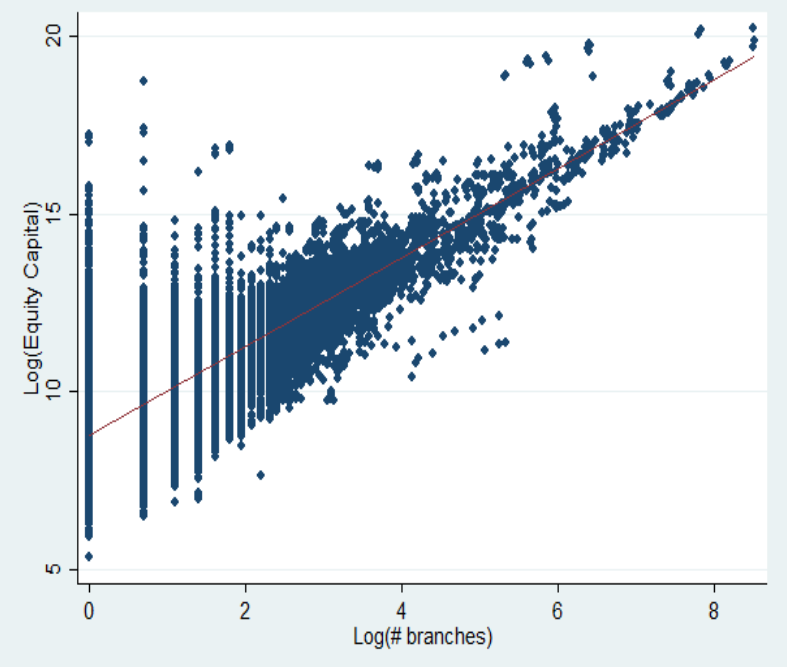

Figure 2: Correlation between equity capital and total number of branches of a bank. The slope of the linear fit is 1.25 .

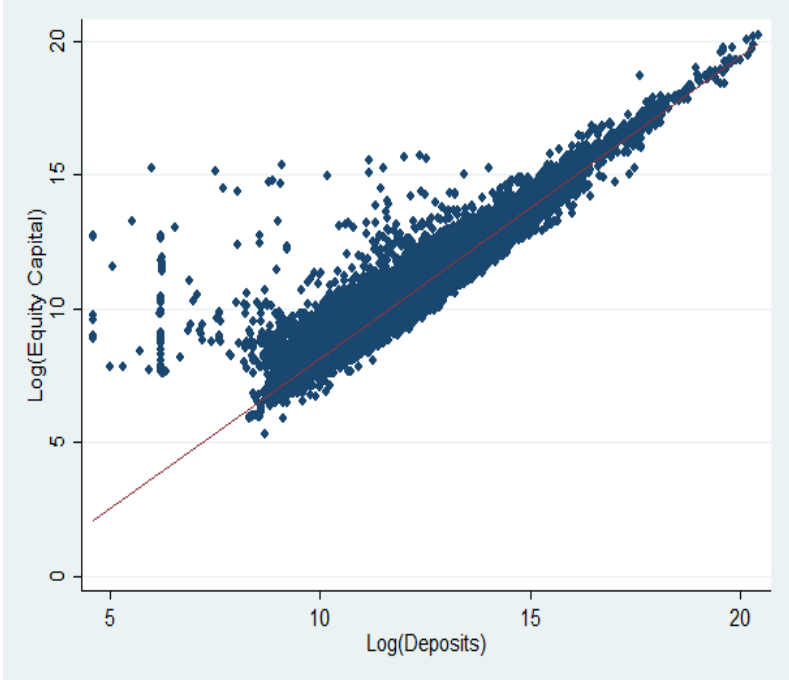

Figure 3: Correlation between equity capital and total deposits of a bank. The slope of the linear fit is 1.13 . 


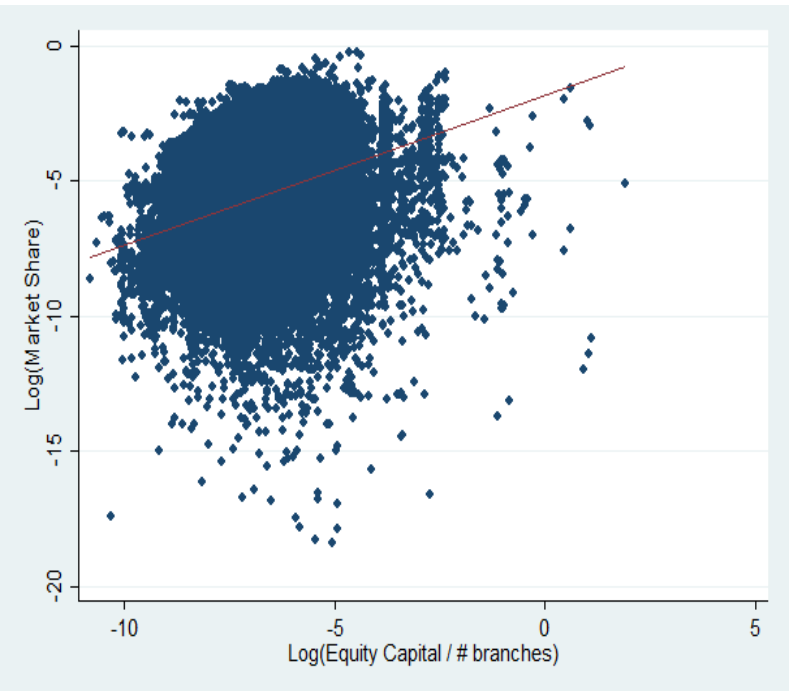

Figure 4: Correlation between market share and the ratio of equity capital to total number of branches. The slope of the linear fit is 0.56 ( $\mathrm{p}$-value $=0.0073)$.

banks shows similar risk profile across both the groups. Finally, the average per capita income comparison between treatment and control groups shows a similar demographic profile of consumers. This suggests that control and treatment markets are similar to each other prior to the first merger occuring in a market.

\begin{tabular}{r|ccccc}
\hline & \multicolumn{5}{c}{ Small Merger Markets } \\
\hline & $\begin{array}{c}\text { Deposit } \\
\text { rate }\end{array}$ & $\begin{array}{c}\text { Loan } \\
\text { rate }\end{array}$ & $\begin{array}{c}\text { Median bank } \\
\text { size }\end{array}$ & $\begin{array}{c}\text { Capital asset } \\
\text { ratio }\end{array}$ & $\begin{array}{c}\text { Per capita } \\
\text { income }\end{array}$ \\
\hline Control & 0.0208 & 0.0701 & 15 & 0.0942 & 28.0117 \\
& 0.0223 & 0.0712 & 11 & 0.0917 & 29.5431 \\
\hline & \multicolumn{5}{c}{ Big Merger Markets } \\
\hline & Deposit & Loan & Median bank & Capital asset & Per capita \\
& rate & rate & size & ratio & income \\
\hline Control & 0.0216 & 0.0710 & 8 & 0.0933 & 29.6648 \\
Treatment & 0.0225 & 0.0711 & 13 & 0.0913 & 29.3284 \\
\hline
\end{tabular}

Table 22: Control and treatment groups : Before period. Means are reported for all variables except the bank size. 